\title{
Delamination Detection of Reinforced Concrete Decks Using Modal Identification
}

\author{
Shutao Xing, ${ }^{1,2}$ Marvin W. Halling, ${ }^{2}$ and Paul J. Barr ${ }^{2}$ \\ ${ }^{1}$ DeepSea (US) Inc., Houston, TX 77042, USA \\ ${ }^{2}$ Department of Civil and Environmental Engineering, Utah State University, Logan, UT 84322, USA
}

Correspondence should be addressed to Marvin W. Halling, marv.halling@usu.edu

Received 9 June 2012; Accepted 3 August 2012

Academic Editor: Andrea Cusano

Copyright (C) 2012 Shutao Xing et al. This is an open access article distributed under the Creative Commons Attribution License, which permits unrestricted use, distribution, and reproduction in any medium, provided the original work is properly cited.

\begin{abstract}
This study addressed delamination detection of concrete slabs by analyzing global dynamic responses of structures. Both numerical and experimental studies are presented. In the numerical examples, delaminations with different sizes and locations were introduced into a concrete slab; the effects of presence, sizes, and locations of delaminations on the modal frequencies and mode shapes of the concrete slab under various support conditions were studied. In the experimental study, four concrete deck specimens with different delamination sizes were constructed, and experimental tests were conducted. Traditional peak-picking, frequency domain decomposition, and stochastic subspace identification methods were applied to the modal identification from dynamic response measurements. The modal parameters identified by these three methods correlated well. The changes in modal frequencies, damping ratios, and mode shapes that were extracted from the dynamic measurements were investigated and correlated to the actual delaminations and can indicate presence and severity of delamination. Finite element (FE) models of reinforced concrete decks with different delamination sizes and locations were established. The modal parameters computed from the FE models were compared to those obtained from the laboratory specimens, and the FE models were validated. The delamination detection approach was proved to be effective for concrete decks on beams.
\end{abstract}

\section{Introduction}

Delamination occurs when the corrosion in the steel rebar induces cracks and the cracks joined together to cause the concrete cover to separate from the substrate concrete. It results in the loss of structural strength and facilitates a rapid deterioration of the deck [1]. The delamination impairs both the appearance and the serviceability of the structure, and repairs can be very costly. It is estimated that annual maintenance and repair costs related to corrosion for concrete infrastructure approach $\$ 100$ billion worldwide $[2,3]$. As a corrosion-induced problem, delamination is of great concern for bridges, and routine inspection is necessary. Many methods have been developed to detect concrete delamination. These methods include the conventional chain drag method, impact-echo, ultrasonic tests, ground penetrating radar, imaging radar, and infrared thermography $[1,4]$. Efforts have been made to expand, improve, and combine currently available techniques. While the conventional methods have been successfully used in the past, they require deployment of professional people with devices to field sites and traffic control which can be very costly. With the expansion of structural health monitoring systems, increasing numbers of real-time monitoring systems are being deployed on actual bridges and buildings. Taking advantage of permanently installed sensors can be useful in delamination detection. Vibration sensors can be flexibly deployed and located insitu for long-term monitoring applications that include delamination detection.

Various analytical, numerical, and experimental studies have addressed delamination detection in composite structures by identification from the measurements of vibration sensors. Zou et al. [5] provided a review of vibration-based model-dependent delamination identification for composite structures. Valdes and Soutis [6] conducted experiments to study the effects of delamination in laminated beams on the changes in modal frequencies. Racliffe and Bagaria [7] used curvature mode shapes to locate delaminations in 
a composite beam. Wei et al. [8] evaluated delamination of multilayer composite plates using model-based neural networks. Yan and Yam [9] employed energy distribution of dynamic responses decomposed by wavelet analysis to detect the delaminations in composite plates and reported that this method is capable of detecting localized damage. Among these studies, most are on simple composite structures such as beams, with very few, if any, studies performed on plates. For civil engineering concrete structures, studies on delamination detection by vibration measurements from structural health monitoring systems are rare. Xing et al. [10] investigated delamination detection by using vibration measurements by sensors for civil engineering concrete plates through numerical studies. In this numerical study, finite element models of the concrete plates were modeled using ANSYS. The modal analyses were performed for examination of the effect of delamination parameters on the modal characteristics of the models. The effectiveness of using changes in modal frequencies and mode shapes as damage indicators of the delamination was studied. The proposed methodology in this paper provides the advantage of a nonsubjective means to quantitatively evaluate bridge decks.

The current study presents an expansion of the previous numerical studies [10] with a more complete parametric study. Additionally, experimental studies of four reinforced concrete slabs with different delamination areas were tested dynamically to verify the numerical results. Delaminations were simulated by embedding plexiglass inside the concrete plates during casting. The dynamic tests were conducted approximately four months after placement of the concrete. The experiments were original and significant since the models were relatively large-scale concrete plates. The models were intended to simulate concrete decks on girder bridges. Initial experimental results were discussed in [11], and a more comprehensive study is addressed in this paper. No similar experimental testing was encountered in the literature.

The primary purpose of this paper is to investigate the applicability of delamination detection of concrete plates by modal identification using dynamic responses measured by vibration sensors. The fundamental principle is that the delaminations decrease the stiffness and consequently the modal frequencies. Additionally, damping increases and mode shapes become irregular; the amplitude of the mode shapes around the delamination area is changed. Taking advantage of the changes in modal characteristics can avoid dealing with the complicated delamination mechanisms, such as the random occurrence and irregular shape and distribution of concrete delamination, which need many parameters to evaluate.

After numerical studies of several finite element models, the experiments were conducted. Since different types of input excitation may influence the dynamic properties estimated from their responses; the experimental testing consisted of dynamic tests using random, swept sine, and impact excitation. The dynamic characteristics estimated from the responses due to these excitations were presented to provide reference for output only systems (ambient vibration). Modal frequencies, modal damping ratios, and mode shapes were extracted from the measured velocity responses. The differences in modal characteristics between the various delaminated models were compared and indicated presence and severity of delaminations. Finite element models of the concrete slabs were also established using ANSYS software. The concrete, steel reinforcement, wood supports, delaminations, and boundary conditions were included in the model. The modal characteristics computed from the finite element models were compared with those from dynamic tests for validation. The finite element results could be used as reference for modal identification from dynamic response measurements.

\section{Modal Identification Methods for the Output Only Systems}

The classical peak-picking (PP), frequency domain decomposition (FDD), and stochastic subspace identification (SSI) methods were used in this study. In the PP method, the peaks of the power spectra of time histories measurements were used to determine modal frequencies. FDD and SSI methods were also adopted to extract modal characteristics from measurements of the dynamic tests.

For lightly damped structures, [12] derived a relationship between response spectral and modal parameters, which provide a basis for FDD method. In application of FDD algorithm, the power spectral density (PSD) of output measurements $\widehat{G}_{y y}(j \omega)$ is estimated and then decomposed at $\omega=\omega_{i}$ by taking the singular value decomposition (SVD) of the PSD matrix:

$$
\hat{G}_{y y}\left(j \omega_{i}\right)=U_{i} S_{i} U_{i}^{H},
$$

where the unitary matrix $U_{i}=\left[u_{i 1}, u_{i 2}, \ldots, u_{i m}\right]$ holds singular vectors $u_{i j}$ and the diagonal matrix $S_{i}$ holds singular values $s_{i j}$. If only a $k$ th mode is dominating at selected frequency $\omega_{i}$, there would be only one singular value in (1). Hence the 1st singular vector $u_{i 1}$ is an estimate of the $k$ th mode shape $\hat{\phi}=u_{i 1}$. Damping can be obtained from the correlation function of the SDOF system [13].

The SSI method is a time-domain identification method proposed in [14]. It has been applied effectively for various types of structures. It can obtain linear models from column and row spaces of the matrices computed from input-output data [15]. This paper used data-driven SSI that does not need computation of output covariance. An enhancement of it, called reference-based SSI method, was presented in [16]. Discrete-time stochastic state-space model is a normal model without input terms [17]:

$$
x_{k+1}=A x_{k}+w_{k} ; \quad y_{k}=C x_{k}+v_{k},
$$

where $w$ is process noise vector, $v$ is observation noise vector; they are independent of each other. The SSI is used to compute $A$ and $C$ from output-only measurements $y_{k}$. 
The identification steps are briefly summarized below, for details, refer to $[15,16]$.

(a) Construct Hankel matrix $Y_{0 \mid 2 i-1}$ from the output measurements:

Hankel matrix $Y_{0 \mid 2 i-1}$ is a matrix that has the same elements in every antidiagonal as shown in (3);

$$
\begin{aligned}
Y_{0 \mid i}= & {\left[\begin{array}{cccc}
y_{0} & y_{1} & \ldots & y_{j-1} \\
y_{1} & y_{2} & \ldots & y_{j} \\
\ldots & \ldots & \ldots & \ldots \\
y_{i-1} & y_{i} & \ldots & y_{i+j-2}
\end{array}\right] ; } \\
Y_{i \mid 2 i-1}= & {\left[\begin{array}{cccc}
y_{i} & y_{i+1} & \ldots & y_{i+j-1} \\
y_{i+1} & y_{i+2} & \ldots & y_{i+j} \\
\ldots & \ldots & \ldots & \ldots \\
y_{2 i-1} & y_{2 i} & \ldots & y_{2 i+j-2}
\end{array}\right] ; } \\
Y_{0 \mid 2 i-1}= & {\left[\frac{Y_{0 \mid i}}{Y_{i \mid 2 i-1}}\right]=\left[\frac{Y_{P}}{Y_{f}}\right], }
\end{aligned}
$$

where subscript of $y$ denotes time instant, $i$ is the total number of block rows and must be greater than the system order $n$, which is the dimension of state matrix $A, j$ is the number of columns, $y_{k}$ is a vector with $l$ rows, which are the degrees of freedom to be measured. $Y_{0 \mid 2 i-1}$ is composed of the past output part $Y_{p}$ and the future output part $Y_{f}$; each part has $i$ block rows and $j$ columns. When SSI is used, the system order can be over specified, and the spurious modes can be eliminated by investigating stabilization diagrams. Due to space limitations, these diagrams are not presented in this paper; the results are verified to be correct with an appropriate system order value. Let $n y$ denote the number of time samples of output $y_{k}$; to guarantee $y_{k}$ populate Hankel matrix, use $j=n y-2 i+1$.

(b) Orthogonally, project the row space of future outputs $Y_{f}$ on the row space of past outputs $Y_{p}$ :

$$
T_{i}=Y_{f} Y_{p}^{T}\left(Y_{p} Y_{p}^{T}\right)^{\dagger} Y_{p}
$$

where ${ }^{T, \dagger}$ denote transpose and pseudoinverse, respectively.

(c) Apply SVD to the orthogonal projection:

$$
T_{i}=U S V^{T}=\left(\begin{array}{ll}
U_{1} & U_{2}
\end{array}\right)\left(\begin{array}{cc}
S_{1} & 0 \\
0 & S_{2}
\end{array}\right)\left(\begin{array}{c}
V_{1}^{T} \\
V_{2}^{T}
\end{array}\right) \approx U_{1} S_{1} V_{1}^{T},
$$

where $U$ and $V$ are orthonormal matrices, $S$ is a diagonal matrix containing singular values in descending order, $S_{2}$ is a block containing neglected values.

(d) Calculate the discrete-time system matrices $A$ and $C$ using (6), which compute the extended observability matrix from SVD of (5) and the definition of it:

$O_{i}=U_{1} S_{1}^{1 / 2} ; \quad O_{i}=\left(\begin{array}{llll}C & C A & \cdots & C A^{i-1}\end{array}\right)^{T}$. (e) Postprocess to extract modal parameters.

The matrices $\Lambda$ and $\psi$ containing eigenvalues and eigenvectors of $A$ are computed using $A=\psi \Lambda \psi^{-1}$. The state matrix of the continuous-time system is $A_{C}=\psi_{C} \Lambda_{C} \psi_{C}^{-1}$. The relationships are shown below:

$$
\begin{aligned}
& A=e^{A_{C} \Delta t} ; \quad \psi_{c}=\psi ; \quad \lambda_{C_{q}}=\ln \frac{\left(\lambda_{q}\right)}{\Delta t} ; \\
& \lambda_{C_{q}}, \lambda_{C_{q}}^{*}=-\xi_{q} \omega_{q} \pm j \omega_{q} \sqrt{1-\xi_{q}^{2}} ; \quad \Phi=C \psi,
\end{aligned}
$$

where $\Delta t$ is time step, $\omega_{q}$ is modal frequency, $\xi_{q}$ is modal damping ratio, $\Phi$ contains mode shapes.

When actual measurements are processed, they result in complex frequencies and complex mode shapes. For lightly damped systems, the magnitudes of the complex mode shapes can be plotted as real mode shapes.

\section{Numerical Studies}

In this section, a finite element model of a reinforced concrete plate was created and then several delaminations of various sizes and locations were introduced into the model, separately. The modal analyses were performed on the model, and the effects of delamination on modal characteristics of the reinforced concrete finite element model were studied to provide useful reference for further numerical studies as well as for the laboratory experiments. The effects of support conditions on the applicability of the proposed method were also examined.

3.1. Description of the Numerical Examples. The reinforced concrete plate of the numerical studies is illustrated in Figure 1. The width $a$ is $4200 \mathrm{~mm}$ along the $X$ direction, the length $b$ is $8000 \mathrm{~mm}$ along the $Z$ direction, and thickness $h$ is $200 \mathrm{~mm}$ along the $Y$ direction, the origin is defined at the bottom corner node; the coordinate system is shown in Figure 1(a). The concrete's elastic modulus is $E_{c}=$ $32500 \mathrm{MPa}$, Poisson's ratio $v_{c}=0.24$, ultimate uniaxial compressive strength is $\sigma_{c}=25.5 \mathrm{MPa}$, ultimate uniaxial tensile strength is $\sigma_{t}=2.56 \mathrm{MPa}$, and density is $\rho_{c}=$ $2400 \mathrm{~kg} / \mathrm{m}^{3}$. The steel rebar's size is $\# 6$, nominal diameter is $d=19 \mathrm{~mm}$, elastic modulus is $E_{s}=200 \mathrm{GPa}$, yield stress is $f_{y}=410 \mathrm{MPa}$; Poisson's ratio is $\nu_{s}=0.3$; and the density is $\rho_{s}=7850 \mathrm{~kg} / \mathrm{m}^{3}$. Two layers of steel rebar are placed in the concrete plate at the horizontal planes of $Y=50 \mathrm{~mm}$ and $Y=150 \mathrm{~mm}$ and rebar are along both $X$ and $Z$ directions as exhibited in Figure 1(b). The space between all adjacent rebar is $200 \mathrm{~mm}$ on center. The concrete plate is simply supported at the two opposite edges $X=0 \mathrm{~mm}$ and $X=4200 \mathrm{~mm}$ and free at the other two opposite edges $Z=0 \mathrm{~mm}$ and $Z=8000 \mathrm{~mm}$. This will be symbolized by SS-F-SS-F.

3.2. Finite Element Modeling. The finite element software, ANSYS, was used to perform the finite element modeling. Solid65 and link8 elements were selected to represent concrete and steel rebar, respectively. Solid65 element has 


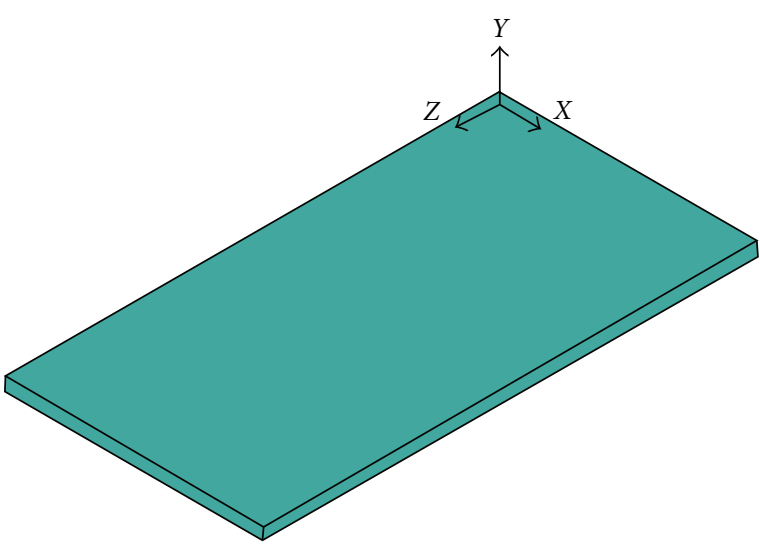

(a)

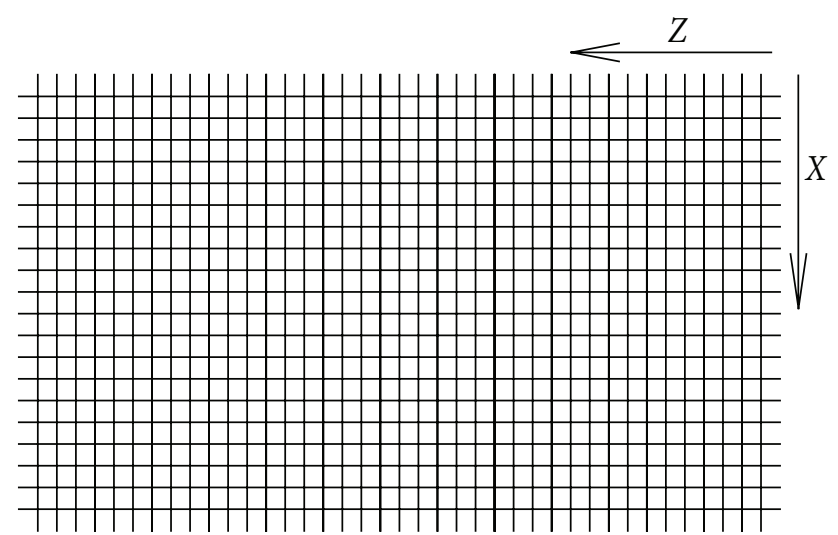

(b)

Figure 1: The concrete slab model, (a) isometric view of the concrete model, (b) plane view of the steel rebar.

eight nodes with three translational degrees of freedom at each node. The reason to use solid65 element is that its capability in modeling concrete may be used in the future studies. The 3D spar, Link8, element is a uniaxial tension-compression element with three translational degrees of freedom at each node [18]. In this paper, all analyses were restricted to linear elastic response and the elements were configured accordingly. When the mesh size of concrete was changed from $50 \mathrm{~mm}$ to $25 \mathrm{~mm}$, the same modal analysis results were obtained without convergence problems.

Delamination was modeled using a similar method to [19]. First, two separate decks that were located above and below the delamination plane were attached together. The nodes in the undamaged area were declared as coupled nodes utilizing coupling/constraint equations and the nodes in delaminated area were uncoupled. The delamination locations and areas were adjusted for different damage degrees. All the delaminations were on the $X Z$ plane at a vertical elevation of $Y$ equal to $150 \mathrm{~mm}$, which was purposely to simulate a bridge deck in which delamination often occurs in a horizontal plane at the top layer of steel reinforcement. In the following sections, the ratio of the delamination area to the total area $A_{\text {delam }} / A_{\text {tot }}$ is used to denote severity of delamination.
TABLE 1: Comparison of frequencies by analytical and finite element model for a numerical example.

\begin{tabular}{lccccc}
\hline Mode & 1 & 2 & 3 & 4 & 5 \\
\hline Analytical solution & 20.91 & 27.99 & 49.49 & 84.32 & 87.02 \\
ANSYS solution & 20.96 & 27.12 & 50.32 & 81.49 & 85.73 \\
Difference (\%) & 0.24 & -3.11 & 1.68 & -3.36 & -1.48 \\
\hline
\end{tabular}

3.3. Modal Frequencies Validation of the Finite Element Models. The analytical solutions for the natural frequencies were computed to validate the modeling. For convenience of using the analytical formula from [20], the Poisson's ratio of the concrete was changed to $v_{c}=0.3$, the dimensions were changed to $a=4000 \mathrm{~mm}$ and $b=6000 \mathrm{~mm}$. The other parameters take same values as those of the model in the above section. In order to use the analytical solution, the equivalent elastic modulus and density were used, which were computed by (8) and (9):

$$
\begin{aligned}
& E\left(A_{c}+A_{s}\right)=E_{c} A_{c}+E_{s} A_{s}, \\
& \rho\left(V_{c}+V_{s}\right)=\rho_{c} V_{c}+\rho_{s} V_{s},
\end{aligned}
$$

where $E$ is the equivalent elastic modulus, $\rho$ is the equivalent density, $V_{c}$ and $V_{s}$ are the volumes of concrete and steel rebar, respectively, $A_{c}, \rho_{c}, \rho_{s}, A_{s}$ have same meanings as those in the above section.

Since minimum of $(a, b) / h$ is equal to $1 / 20$, it can be analyzed as thin plate and Kirchhoff assumptions are applicable. The analytical method follows [20]. The governing equation is

$$
D \nabla^{4} w+\rho \frac{\partial^{2} w}{\partial t^{2}}=0
$$

where $w$ is transverse deflection, $\nabla^{4}$ is biharmonic differential operator in rectangular coordinates, $D=E h^{3} / 12(1-$ $\left.v^{2}\right)$ is the flexural rigidity. The boundary conditions for the simply supported and free edges are (11) and (12) accordingly:

$$
\begin{array}{rlrl}
w & =0 ; & & \frac{\partial^{2} w}{\partial x^{2}}+v \frac{\partial^{2} w}{\partial z^{2}}=0 \\
\frac{\partial^{2} w}{\partial x^{2}}+v \frac{\partial^{2} w}{\partial z^{2}}=0 ; & \frac{\partial^{3} w}{\partial x^{3}}+(2-v) \frac{\partial^{3} w}{\partial x \partial z^{2}}=0 .
\end{array}
$$

Combining (10)-(12), characteristic equations that can numerically solved by Newton's method to yield the frequency parameter can be written as

$$
\lambda=\omega a^{2} \sqrt{\frac{\rho}{D}} .
$$

Equation (13) can be used to calculate the natural frequencies. The comparison results are listed in Table 1. The percent differences are within $3.4 \%$ for the first five frequencies, and the difference for the first frequency is only $0.24 \%$. It is shown that most frequencies by analytical solution were a little larger than those by modeling. This is reasonable, because thin plate theory usually overestimates the natural 
TABLE 2: The locations and sizes of the delaminated areas for numerical example.

\begin{tabular}{lccccccc}
\hline$A_{\text {delam }} / A_{\text {tot }}$ & $1 / 8$ & $1 / 6$ & $1 / 5$ & $1 / 4$ & $1 / 3$ unsymmetrical & $1 / 3$ symmetrical & $1 / 2$ \\
\hline$X(\mathrm{~mm})$ & $100 \sim 2149$ & $100 \sim 2466$ & $100 \sim 2692$ & $100 \sim 2998$ & $100 \sim 3447$ & $427 \sim 3773$ \\
$Z(\mathrm{~mm})$ & $100 \sim 2149$ & $100 \sim 2466$ & $100 \sim 2692$ & $100 \sim 2998$ & $100 \sim 3447$ & $2327 \sim 5673$ \\
$Y(\mathrm{~mm})$ & 150 & 150 & 150 & 150 & 150 & $100 \sim 4199$ \\
\hline
\end{tabular}

frequencies [21] and Mindlin Plate theory would be more accurate for a thick plate. Therefore, based on the results, it was concluded that the finite element model accurately produced the correct modal frequencies.

3.4. Modal Analysis of the Finite Element Models. The modal analysis was carried out to correlate the delamination with modal characteristics. The analysis was confined to the first 6 modes. Table 2 provides the sizes and locations for the delamination cases of this study. Table 3 shows the comparisons of modal frequencies of the undamaged model and those of different delaminated models under SS-F-SS$\mathrm{F}$ support. The percent differences reported in Table 3 were calculated relative to the undamaged model. Figures 2-3 compare the 3rd-mode shapes from the undamaged and delaminated models. The modal amplitudes shown in the figure have been scaled by the same factor. The modal order is the subnumber in the figures minus one for this analysis.

Based on the frequency variation listed in Table 3 , it is clear that the higher the modal order is, the larger the reduction of the modal frequency is. The changes in the 4 th modal frequency are much larger than their neighboring modes, which indicate that specific modes are more sensitive to delamination than other modes. Table 3 shows that the larger the delamination areas, the larger percentage reduction of the corresponding frequencies. It is also found that when $1 / 8 \leq A_{\text {delam }} / A_{\text {tot }} \leq 1 / 6$, the changes in the 4 th frequencies can indicate the delamination quite well with frequency difference from $8.42 \%$ to $26.59 \%$, while the changes in the first three frequencies are not greater than $3 \%$. For $1 / 6<$ $A_{\text {delam }} / A_{\text {tot }} \leq 1 / 4$, the changes in the 3 rd frequencies can indicate delamination with frequency difference from $6.63 \%$ to $19.57 \%$. When $1 / 3 \leq A_{\text {delam }} / A_{\text {tot }} \leq 1 / 2$ without consider the $1 / 3$ symmetrical case, the changes in the 1 st frequencies can indicate delamination with frequency difference from $6.39 \%$ to $29.64 \%$. However, when $A_{\text {delam }} / A_{\text {tot }}<1 / 8$, the changes in first four frequencies are within $3 \%$, which can not indicate delamination, and the exhaustive results for the cases of these small delamination areas are not listed.

Similar trends were found to be present in the mode shapes shown in Figures 2-3. While the mode shapes are more sensitive to the delamination and are able to show the location from the irregular curves at the delaminated locations. There are also larger amplitudes at the delaminated locations than the corresponding part of the undamaged model. Comparing the delamination locations in Table 2 with the mode shapes in Figure 2, the irregular parts correspond almost exactly to where the delamination location occurs.

In Table 3, the frequencies of 1/3-unsymmetricaldelaminated and 1/3-symmetrical-delaminated models are listed. The frequency differences between the delaminate models and the undamaged model show that the more unsymmetrical the delamination is, the larger the modal frequencies decrease. For example, the frequencies difference for the 1st frequency of 1/3-symmetrical-delaminated model is $3.10 \%$, but the difference increases to $6.39 \%$ for the $1 / 3$-unsymmetrical-delaminated model. This is also demonstrated by the mode shapes in Figure 3, in which the 1st mode shapes of the two 1/3-delaminated models are illustrated. It is shown that the mode shapes of the unsymmetrical-delaminated model are more irregular and have larger amplitude at the delaminated location than that of the symmetrical delaminated model.

\subsection{The Applicability of the Proposed Approach to Different} Support Conditions. The support conditions of the above numerical examples were changed to two different conditions to examine the effectiveness of the proposed approach for concrete slabs under various boundary conditions.

For the first case, the SS-F-SS-F was changed to C-FC-F, which symbolizes clamped-free-clamped-free support. The concrete deck was clamped at the two opposite edges $X=0$ and $X=4200 \mathrm{~mm}$ and free at the other two opposite edges. The modal analyses were performed for the undamaged and delaminated models under C-F-C-F support condition. The modal frequencies for these models and the percent difference were listed in Table 4 . By comparing the results listed in Tables 4 and 3, it is observed that for the first three or four modes, the C-F-C-F case has larger difference, and for the higher modes, the simply supported have larger difference. This indicates that the performance of the proposed approach is better when the restraints increase.

For the second case, the concrete deck was supported on steel beams at the two opposite edges $X=0$ and $X=4200 \mathrm{~mm}$ and free at the other two opposite edges. The isometric view of the model is shown in Figure 4. The beams were supported over columns. The beams were clamped at the corner of $X=4200$ and $Z=0 \mathrm{~mm}$, free along $Z$ at the corner of $X=0$ and $Z=0 \mathrm{~mm}$, free along $X$ and $Z$ at the corner of $X=0$ and $Z=8000 \mathrm{~mm}$, free along $X$ at the corner of $X=4200$ and $Z=8000 \mathrm{~mm}$. Each beam has a length of $8000 \mathrm{~mm}$ and a rectangular section of $400 \times 400 \mathrm{~mm}$. The steel beams had same material properties with the steel rebar. This support condition is closer to the actual bridge decks supported on steel girders. The modal frequencies related to bending of the decks for the undamaged and delaminated models under this support condition, and the percent difference were listed in Table 5. Figure 5 shows the typical mode shapes for the undamaged and the delaminated models. It is observed from these results that the changes in modal characteristics can indicate delamination. 


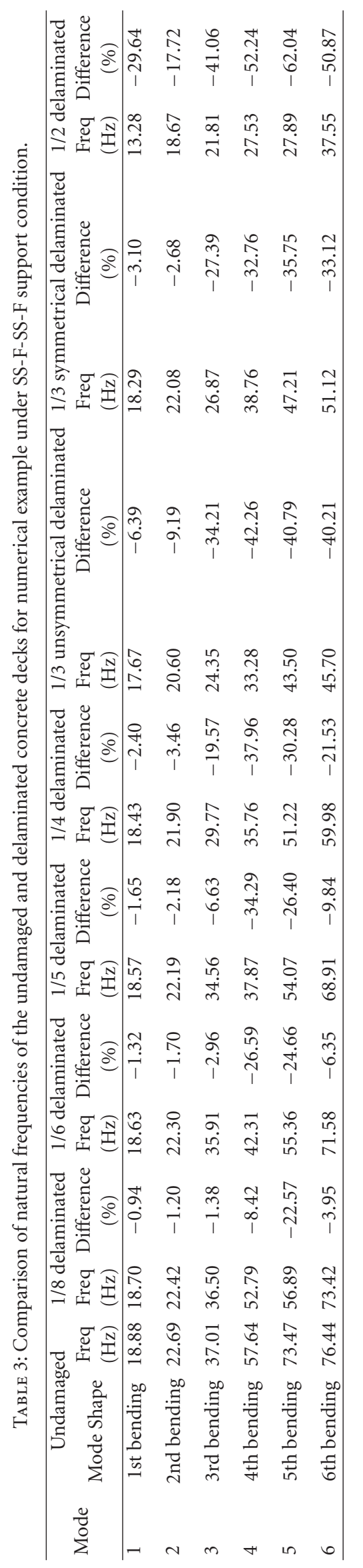




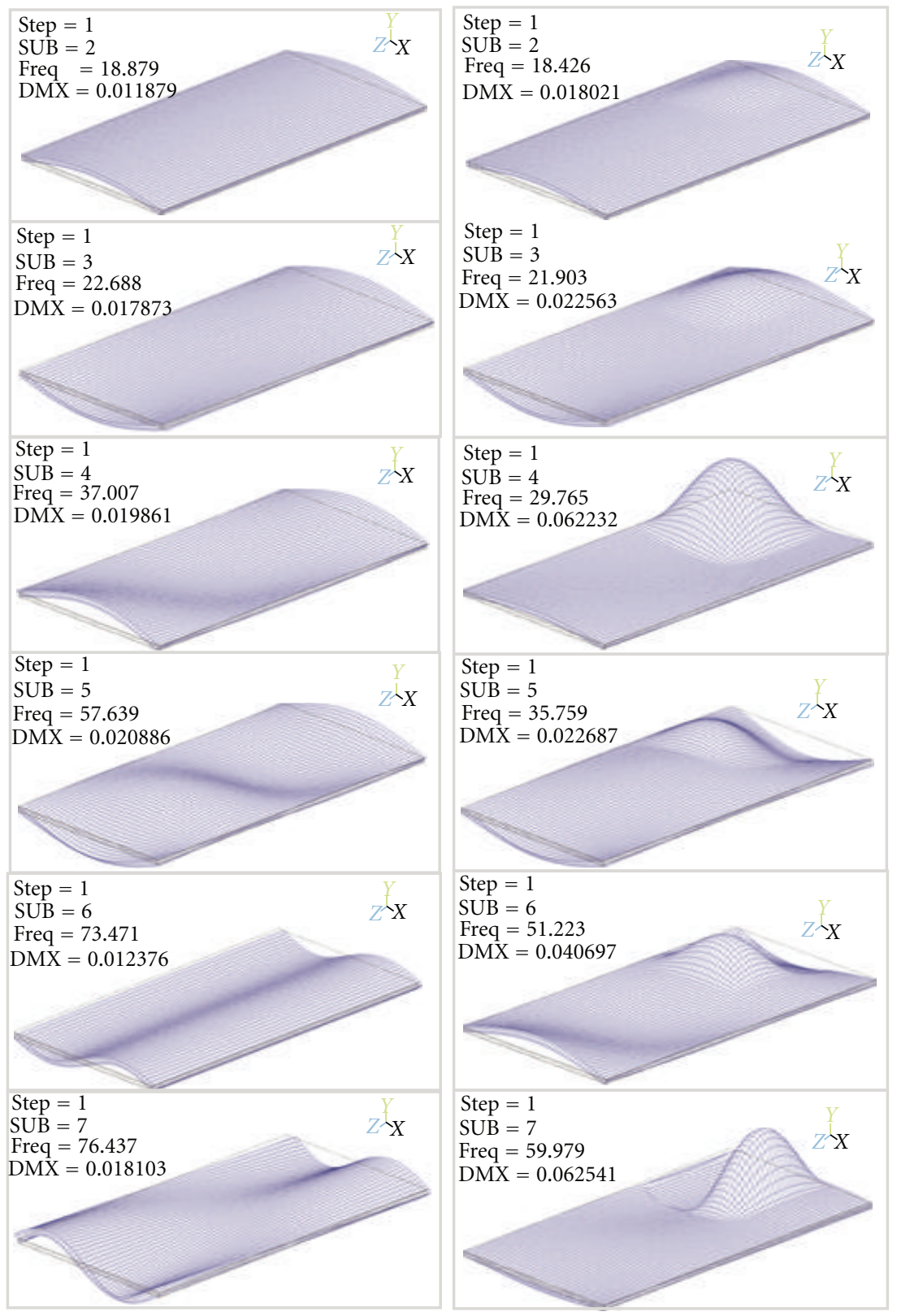

Figure 2: The comparison of the first six mode shapes of two models (left is for the undamaged and right is for the $1 / 4$ delaminated models).

It is found that the general conclusions from the case of SS-F-SS-F still apply to the case of C-F-C-F and the case of supported on beams. While the most sensitive mode and the percentage differences vary. When the proposed method for delamination detection is used, it is necessary and beneficial to perform modal analysis for the specific structures.

\section{Experimental Studies}

The objective of the experimental studies is to investigate the feasibility of delamination detection of concrete structures from real vibration measurements. The general conclusions from this section can be used to verify the previous numerical studies. In the experimental studies, four reinforced concrete plates with simulated delaminations were constructed in the Systems, Materials, and Structural Health Laboratory (SMASH) at Utah State University. Modal characteristics were extracted from the dynamic test data using three modal identification methods. The changes in modal characteristics were used for delamination detection. The finite element models, in this section, were developed for the experimental concrete slabs and the modal analyses based on the structural properties were carried out. Some useful conclusions were drawn from the studies.

4.1. Experimental Setup and Dynamic Tests. Four reinforced concrete plates were constructed in the SMASH lab. Each concrete plate has the same size $1.83 \mathrm{~m} \times 2.74 \mathrm{~m} \times 0.14 \mathrm{~m}$ 


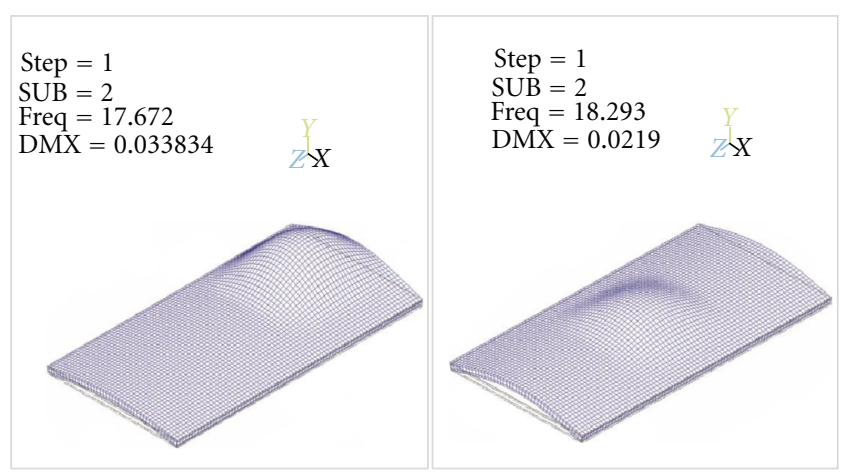

FIgUre 3: Comparison of the 1st mode shapes of the two $1 / 3$ delaminated models (left and right are for a unsymmetrical and a symmetrical model, respectively).

and same layout of \#6 steel rebar as illustrated in Figure 6. All the concrete was placed from the same ready mix concrete batch in order to achieve similar concrete strengths between test specimens. The only differences between the models were the different delamination scenarios that were introduced into the concrete plates.

In the delamination detection studies of composites $[6,7]$, to generate the effects of delamination, Teflon films were inserted into the composite beams/plates to prevent layers from bonding together. In this study, plexiglass sheets $(1.57 \mathrm{~mm}$ thick) were used to simulate the effect of a delamination. Plexiglass is unaffected by moisture and offers a high strength-to-weight ratio, which is good for preventing the bonding of concrete above and below it. One layer of plexiglass was placed into the horizontal plane of each delaminated concrete plate that was $139.7 \mathrm{~mm}$ from the bottom of the plate during the concrete pouring. The horizontal areas of the delaminations were adjusted in each specimen. The first specimen had no delamination and is referred to as undamaged. The other three specimens had delamination sizes of $914 \mathrm{~mm} \times 1219 \mathrm{~mm}$ (22.2\% delamination), $1219 \mathrm{~mm} \times 2134 \mathrm{~mm}(51.9 \%$ delamination $)$ and $1524 \mathrm{~mm} \times$ $2438 \mathrm{~mm}$ ( $74.1 \%$ delamination), respectively. Figure 7 shows the plan and elevation views of the undamaged and all delaminated specimens. Four months after concrete placing, the dynamic tests were performed. During the tests, the two long edges of each concrete plate were placed on timber supports, while the two short edges were unsupported. All of the concrete slabs were tested with the same boundary conditions.

Based on the 28 day concrete compression and tensile tests, the concrete's elastic modulus is $E_{c}=24000 \mathrm{MPa}$, ultimate uniaxial compressive strength is $\sigma_{c}=27.5 \mathrm{MPa}$, ultimate uniaxial tensile strength is $\sigma_{t}=14.69 \mathrm{MPa}$. The concrete density is $\rho_{c}=2300 \mathrm{~kg} / \mathrm{m}^{3}$. Poisson's ratio of concrete is $v_{c}=0.15$. The steel rebar's size is \#6, its nominal diameter is $d=19 \mathrm{~mm}$, elastic modulus is $E_{s}=200 \mathrm{GPa}$, yield stress is $f_{y}=410 \mathrm{MPa}$, Poisson's ratio is $v_{s}=0.3$, and the density is $\rho_{s}=7850 \mathrm{~kg} / \mathrm{m}^{3}$. It needs to be noted that Poisson's ratios of wood are difficult to be measured accurately for they vary within and between species and are affected by moisture content and specific gravity [22].
According to the literature [22-24] and finite element model updating, the timber's anisotropic properties are as follows. The timber's density is $430 \mathrm{~kg} / \mathrm{m}^{3}$. The elastic moduli along the longitudinal, radial, and tangential axes of timber are denoted by $E_{Z}, E_{X}$, and $E_{Y}$; they are $E_{Z}=8 \mathrm{GPa}, E_{X}=0.068 \times$ $E_{Z}$, and $E_{Y}=0.05 \times E_{Z}$. The values of Poisson's ratios $\nu_{Z X}=$ $0.496, \nu_{X Y}=0.56$ and $\nu_{Y Z}=0.274$ were used in this study.

The same dynamic tests were performed on the four specimens for convenience of comparisons. Figure 8 illustrates the layout of excitation sources and sensors. An electromagnetic shaker was employed to generate excitations. Because hammer is convenient and more often used in field tests, the hammer was also used to simulate more practical situations. Based on the identified results from the impulse excitations by shaker and hammer, the two impulses don't make difference. Six velocity transducers $(V 1 \sim V 6)$ were used to measure the vertical responses and one velocity transducer $(V 7)$ was used to measure the horizontal responses. An accelerometer was attached to the shaker to measure the real excitation inputs, and the input acceleration of the instrumented hammer was also measured. These measurements were recorded by a data physics vibration controller/signal analyzer, in which the antialiasing filter was integrated. For the dynamic tests, the APS shaker generated swept sine, random and impulse excitations on the specimens in sequence. Then the instrumented hammer applied impact excitations a few times on two locations. The goal was to detect delamination from the ambient vibration data. Therefore only response measurements were used for modal identification, and frequency response functions (FRFs) were not calculated. The typical swept sine, random, and impact acceleration inputs and the power spectral density (PSD) of them are shown in Figure 9 for the $74.1 \%$ delaminated specimen. The PSD plots in this figure show that all the excitations have frequency bands from 0 to $400 \mathrm{~Hz}$ and similar power distributions over the bands, which ensure that each excitation method has consistent frequency band and power over it. The inputs for the other specimens were similar. The velocity responses and the acceleration inputs were recorded for subsequent analyses. The signal-to-noise ratios (SNRs) for the response measurements by sensors $V 1 \sim V 7$ were estimated to be $54 \sim 58 \mathrm{db}$ under hammer impact excitation, and the numbers were decreased to $18 \sim$ $30 \mathrm{db}$ or lower when the specimens were under shaker excitation. The modal identification showed that same results were obtained from these different responses, which means that the different SNR values had little influence on modal identification results, and all the response measurements were good to provide modal information. The recorded duration for each input by the shaker and hammer was 32 seconds. The sampling frequency was $1024 \mathrm{~Hz}$, theoretically modal frequencies as high as $512 \mathrm{~Hz}$ could be identified; in reality the lower frequencies are critical.

4.2. Modal Identification of the Dynamic Measurements. Classical peak-picking, frequency domain decomposition, and stochastic subspace identification methods were used to 
TABle 4: Comparison of natural frequencies of the undamaged and delaminated concrete decks for numerical example under C-F-C-F support condition.

\begin{tabular}{lcccccccc}
\hline & \multicolumn{2}{c}{ Undamaged } & \multicolumn{2}{c}{$1 / 6$ delaminated } & \multicolumn{2}{c}{$1 / 5$ delaminated } & \multicolumn{2}{c}{$1 / 4$ delaminated } \\
Mode & Mode shape & Freq & Freq & Difference & Freq & Difference & $\begin{array}{c}\text { Freq } \\
(\mathrm{Hz})\end{array}$ & $\begin{array}{c}\text { Difference } \\
(\%)\end{array}$ \\
\hline 1 & 1st bending & 29.19 & 28.06 & -3.87 & 27.50 & -5.79 & 25.54 & -12.51 \\
2 & 2nd bending & 31.96 & 31.02 & -2.96 & 30.74 & -3.81 & 30.05 & -5.98 \\
3 & 3rd bending & 41.76 & 39.82 & -4.63 & 36.82 & -11.83 & 33.23 & -20.43 \\
4 & 4th bending & 60.66 & 43.60 & -28.13 & 41.32 & -31.89 & 39.89 & -34.23 \\
5 & 5th bending & 73.71 & 57.95 & -21.38 & 56.44 & -23.43 & 53.08 & -28.00 \\
6 & 6th bending & 76.94 & 72.13 & -6.25 & 69.77 & -9.32 & 60.70 & -21.11 \\
\hline
\end{tabular}

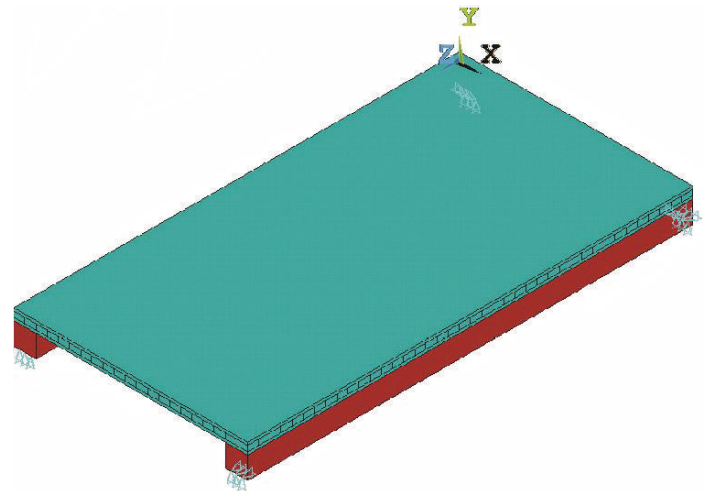

FIGURE 4: The isometric view of the concrete deck supported on beams.

obtain the modal parameters from the velocity responses. Typical time signals and PSD of them for the PP method are shown in Figure 10 for the vertical responses due to swept sine, random, and impact excitations, respectively. Typical singular value plots by FDD for the undamaged model are shown in Figure 11.

The time histories of responses in Figures 10(b) and 10(c) are associated with same external excitations, and therefore they can be compared. It is obvious that the amplitudes of responses of the delaminated model are larger than those of the undamaged model. For example, in Figure 10(b), the response of the delaminated model is about 2 times of the response of the undamaged model.

Applying the SSI method in this study, the system order was $n=60$, and the number of block rows was $i=400$; however, when taking $n=30$ and $i=150$ there was an insignificant change in the results. The issue on how to select the system order is not studied deeply in this paper. The modal frequencies extracted by using PP, FDD, and SSI methods are listed in Table 6 and the damping ratios identified by the SSI method are listed in Table 7 . Figure 12 includes comparisons of the mode shapes of a specified mode for all the concrete slabs obtained by the FDD and SSI methods. For the purpose of convenient comparison, the socalled mode shapes in Figure 12 are plotted with respect to the velocity transducer numbers $V 1 \sim V 6$ instead of the real locations of the $V 1 \sim V 6$ in three dimensions.
The modal frequencies extracted from transducers $V 1-$ $V 6$ vary by a maximum of only $2 \%$ for the presented results; only the results from $V 4$ and $V 7$ are shown in the figures for illustration. The frequencies listed in the tables are also identified from these selected sensors. In Table 6, the frequencies identified by the three methods agree very well for most modes, the differences between the 1st bending frequencies by these methods for all the specimens are less than 2\%. From the comparisons in Figure 12, it is evident that the mode shapes extracted by the FDD and SSI methods yield consistent results. While this paper mainly demonstrates analyses on the responses due to random and impact excitations, the modal characteristics obtained from responses due to all three different excitations match very well, for example, the differences between the 1st frequencies obtained from responses due to random and impact excitations are within $2.5 \%$. In other words, excellent agreements are obtained for modal frequencies and mode shapes regardless of the different identification methods and different excitation inputs, and this validates that the extracted modal characteristics are correct for the dynamic test data.

The effectiveness of using changes in modal frequencies and mode shapes as damage indicators of delaminations is examined in Figures 8, 9, 10, 11 and Tables 4-5. Figure 10 shows that the fundamental frequencies of the delaminated specimens are decreased compared with that of the undamaged specimen. It can also be observed that vibration energy of the response of the undamaged specimen is concentrated in the first few modes; however, the delaminated specimens exhibit a relatively higher level of response in the higher modes. The same conclusions can be drawn from the results for the $51.9 \%$ and $74.1 \%$ delaminated specimens. From Table 6, it can be seen that the corresponding frequencies decrease with the increase of delamination size, among which the 1st bending frequency decreases from $31.77 \mathrm{~Hz}$ to $24.01 \mathrm{~Hz}$. The $22.2 \%$ delaminated specimen was supposed to have higher frequencies than the corresponding ones of $51.9 \%$ delaminated specimen, while they are slightly lower than expected values. This is because the $22.2 \%$ delaminated specimen was the first model to have plexiglass placed, and the building process was slower than the other delaminated models, which slightly reduced the integral strength. 
TABLE 5: Comparison of natural frequencies of the undamaged and delaminated concrete decks for numerical example supported on beams.

\begin{tabular}{|c|c|c|c|c|c|c|}
\hline \multirow[b]{2}{*}{ Mode } & \multicolumn{2}{|c|}{ Undamaged } & \multicolumn{2}{|c|}{$1 / 4$ delaminated } & \multicolumn{2}{|c|}{$1 / 3$ delaminated } \\
\hline & Mode shape & $\begin{array}{l}\text { Freq } \\
(\mathrm{Hz})\end{array}$ & $\begin{array}{l}\text { Freq } \\
(\mathrm{Hz})\end{array}$ & $\begin{array}{c}\text { Difference } \\
(\%)\end{array}$ & $\begin{array}{l}\text { Freq } \\
(\mathrm{Hz})\end{array}$ & $\begin{array}{c}\text { Difference } \\
(\%)\end{array}$ \\
\hline 1 & 1st bending & 11.51 & 11.47 & -0.37 & 11.43 & -0.68 \\
\hline 2 & 2nd bending & 17.91 & 17.80 & -0.62 & 17.65 & -1.45 \\
\hline 3 & 3rd bending & 22.19 & 21.26 & -4.19 & 19.38 & -12.70 \\
\hline 4 & 4th bending & 24.33 & 23.86 & -1.92 & 23.34 & -4.07 \\
\hline 5 & 5th bending & 37.39 & 30.05 & -19.63 & 25.00 & -33.13 \\
\hline 6 & 6th bending & 47.81 & 35.97 & -24.77 & 33.57 & -29.78 \\
\hline
\end{tabular}
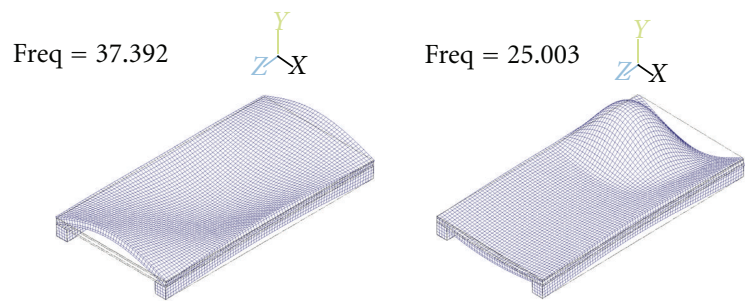

FIGURE 5: Comparison of the 5th mode shapes of the undamaged (left) and $1 / 3$ delaminated (right) models supported on beams.

From Table 7, it is observed that generally the listed damping ratios of the corresponding mode show a trend of increase with the increase of delamination size from $1.05 \%$ $(1.25 \%)$ to $1.71 \%(1.43 \%)$. The damping ratios can assist in identifying delamination, but it is not recommended to rely on damping alone due to the complexity of damping mechanism and difficulty in obtaining accurate damping values in experimental studies. Figure 12 displays the changes in corresponding mode shapes for different delaminated models based on responses due to random excitation. The mode shapes demonstrate that when delamination develops to an undamaged area, the relative amplitude of this area with respect to its neighboring areas becomes larger. Because of the insufficient number of sensors in this study, detailed results are not very accurate regarding the use of mode shapes for the detection of delaminations. It is recommended that additional work is to be performed with denser array of sensors in order to obtain more conclusive results regarding mode shapes.

For real bridges, different types of damage or combination of them may exist. It is challenging to distinguish the changes in modal characteristics caused by the different types of damage. If delamination area is small, it may be hard to determine whether the changes in modal characteristics attribute specifically to delamination instead of concrete spalling or part loss of section stiffness. Further investigations of damage characteristics of delamination may be needed to address this issue.

4.3. Finite Element Modeling of the Experimental Models. The finite element models of the reinforced concrete specimens were created using ANSYS software. The origin of the coordinate system is at the left bottom corner as shown in Figure 7. The longitudinal steel rebar were placed in the model at the plane of $Y=50.8 \mathrm{~mm}$. The transversal rebar were placed immediately above the longitudinal rebar. The two long edges were supported on timber, while the two short edges were unsupported. Solid65, link8, and solid45 elements were selected to represent concrete, steel rebar, and timber, respectively. The laboratory floor was modeled using solid65 elements with infinite strength. Dynamic characteristics are sensitive to the boundary conditions, so the timber supports were modeled realistically instead of as ideal simple supports. Contact and target elements were used to simulate the contact between the concrete and timber and between the timber and the concrete lab floor. The contact and target elements used in this study were conta173 and targe170 elements, respectively. Coefficient of friction was an important parameter and was the only parameter needed to be adjusted for the different delaminated models. Its values range between 0.28 and 0.32 . Normal penalty stiffness factor FKN can be a small value less than 0.1 , and the penetration tolerance factor FTOLN can be 0.1 . The properties of the contact elements were updated to match the results of modal analysis from real measurements. The delaminations were modeled by reducing the elastic modulus of the delaminated parts to very small numbers. In the modeling process, the mass of the shaker was also included in some models and found to be negligible, particularly for the lower modes.

Modal analyses of all of the four reinforced concrete slab specimens were performed. The computed modal frequencies and mode shapes were compared with those from experimental tests. Comparisons of frequencies are listed in Table 8 and one mode shape of the undamaged and delaminated models are shown in Figure 13. Figure 13 shows that the irregular part of the mode shape locates where delamination occurs. Table 8 demonstrates that the lowest and even relatively high-order modal frequencies calculated by ANSYS model match those from dynamic testing well; the difference between the ANSYS model and FDD method from test data for the first three frequencies is maximally $7 \%$. Figure 13 shows that the frequencies of the delaminated models decrease and the mode shapes have abrupt changes at the delaminated areas. The comparison of mode shapes by the Ansys modeling with those by the FDD and SSI methods from the response measurements due to random excitation is shown in Figure 12. It is observed that the mode shapes of 


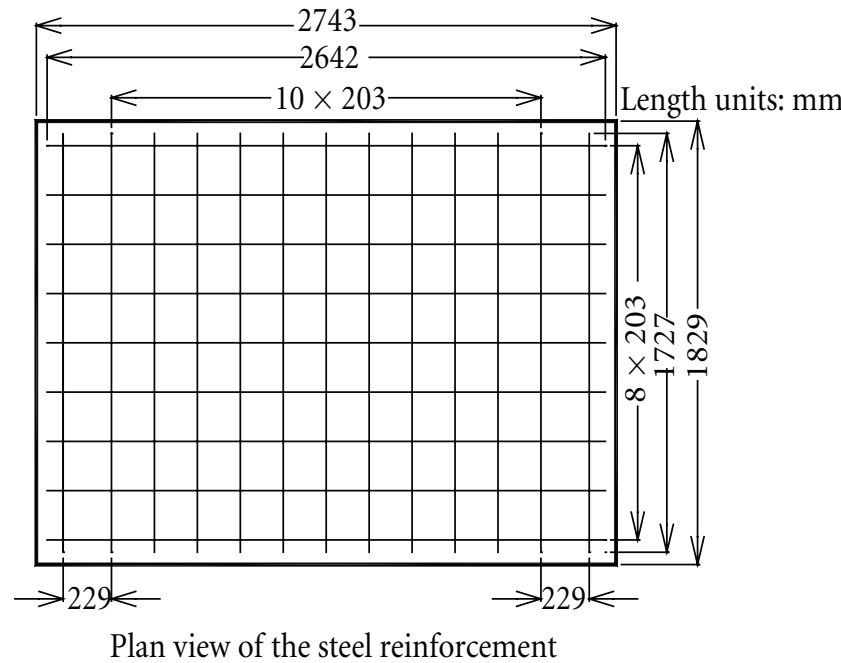

(a)

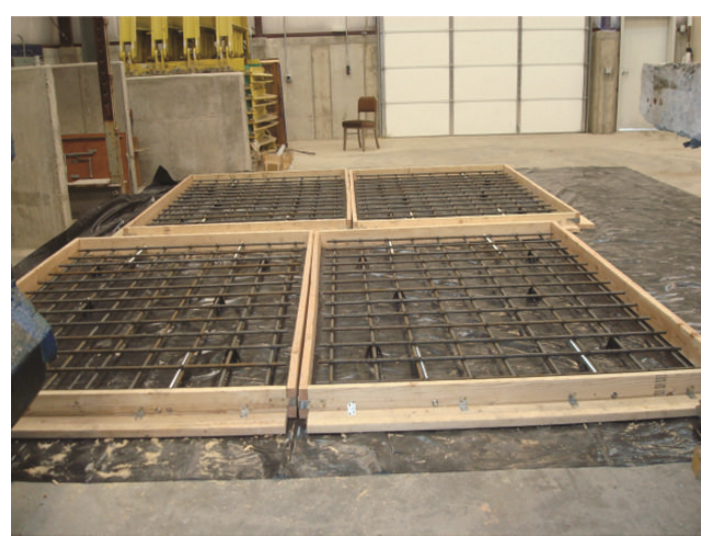

(b)

Figure 6: Plan view of steel reinforcement. (a) Drawing of the plan view of steel reinforcement; (b) formwork.

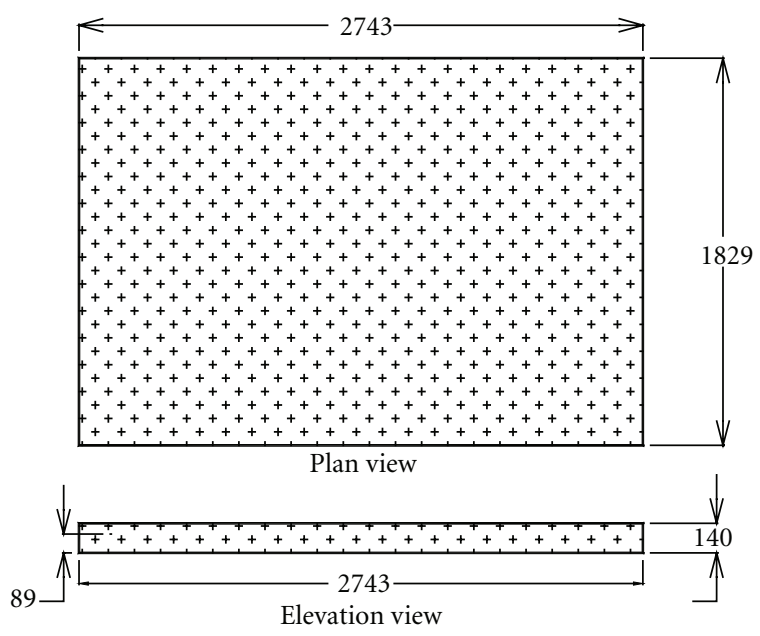

(a)

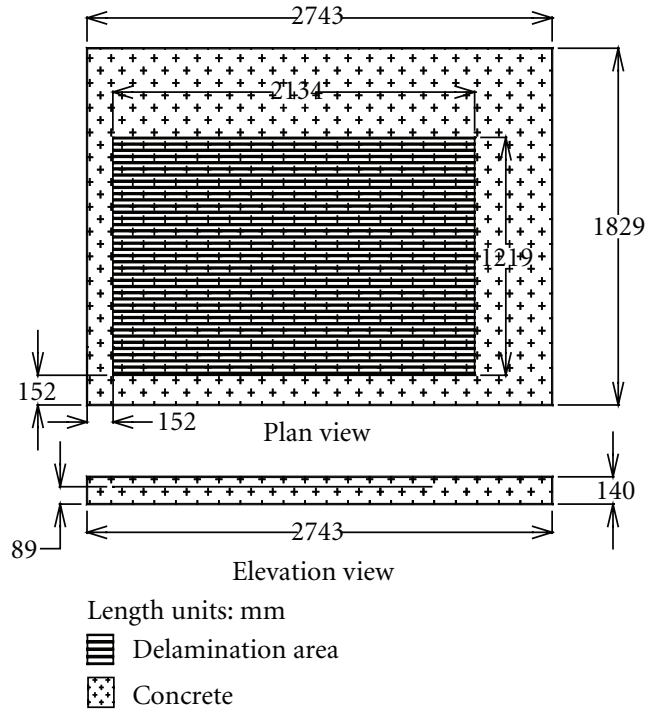

(c)

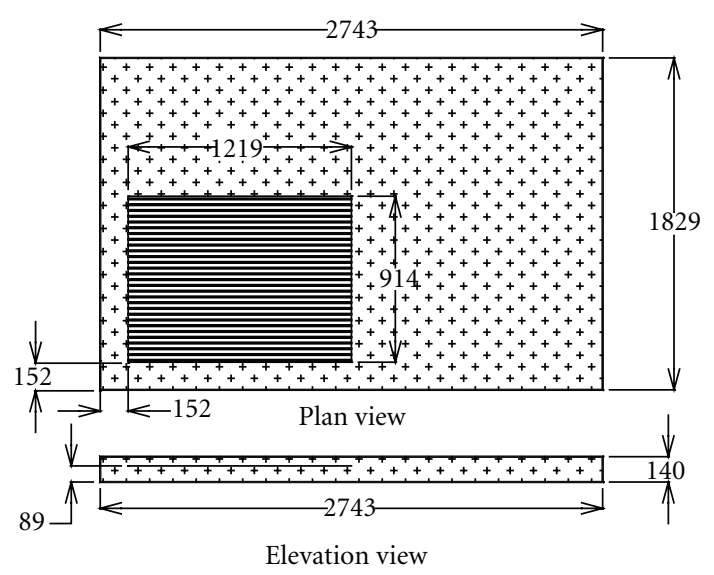

(b)

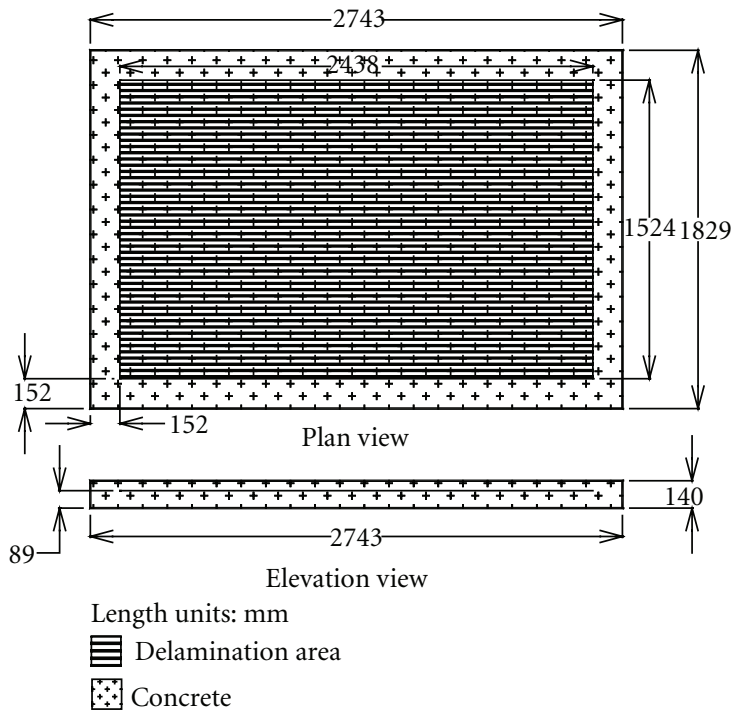

(d)

Figure 7: The locations of delamination areas (plexiglass) for the experimental concrete plates: (a) undamaged model; (b) 22.2\% delaminated model; (c) $51.9 \%$ delaminated model; (d) $74.1 \%$ delaminated model. 


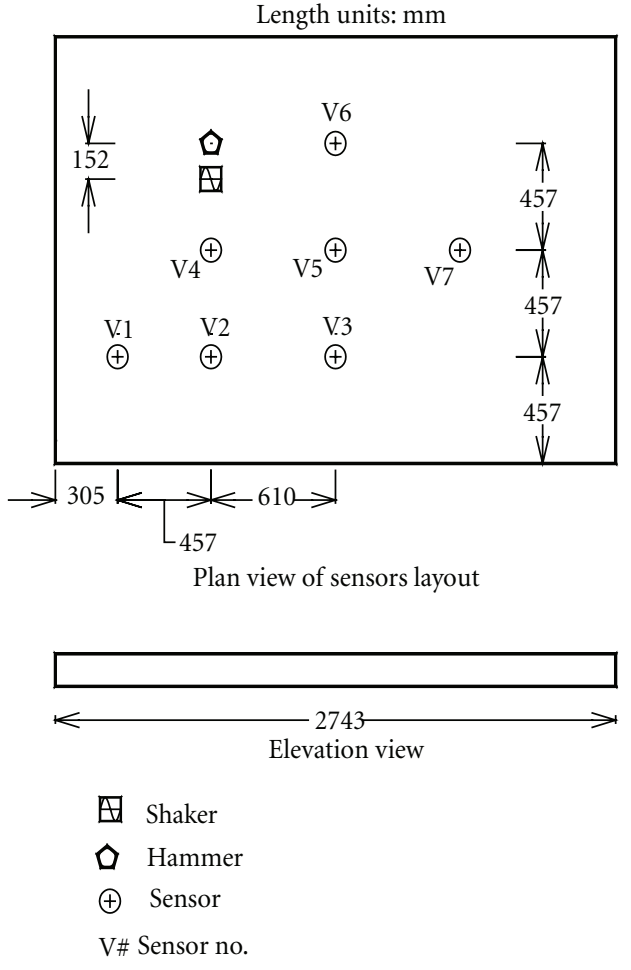

(a)

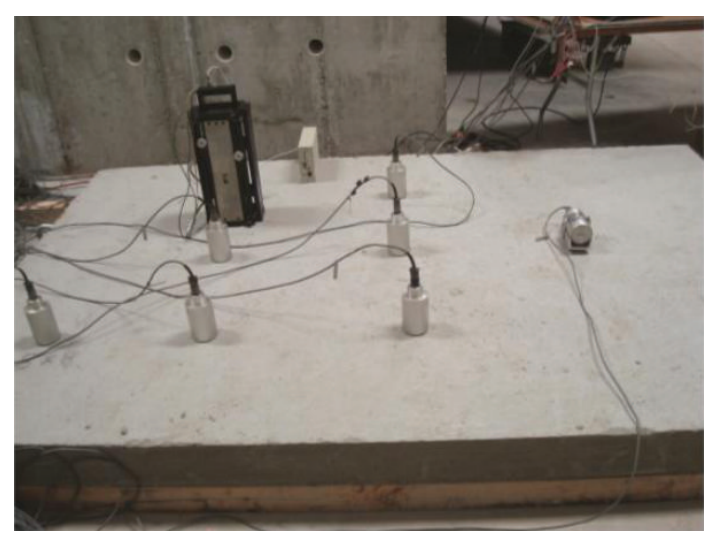

(b)

FIGURE 8: Layout of excitation sources and sensors for dynamic tests: (a) layout of excitation sources and sensors, (b) one of the models for dynamic test.

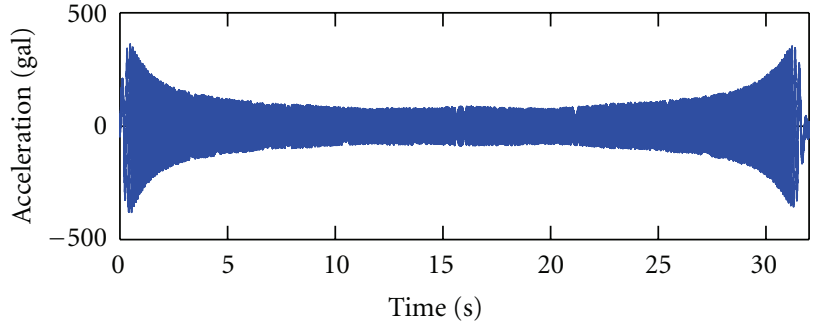

(a)

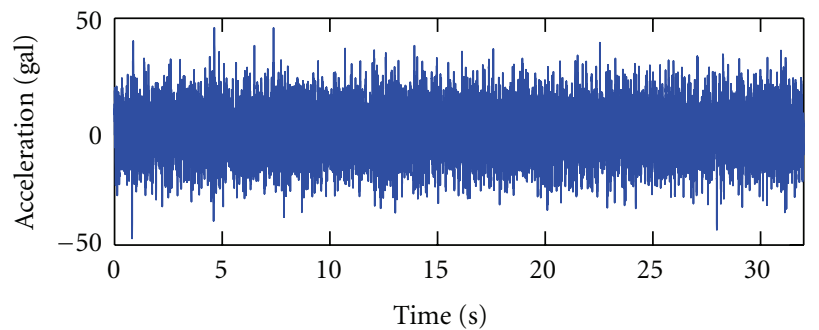

(c)

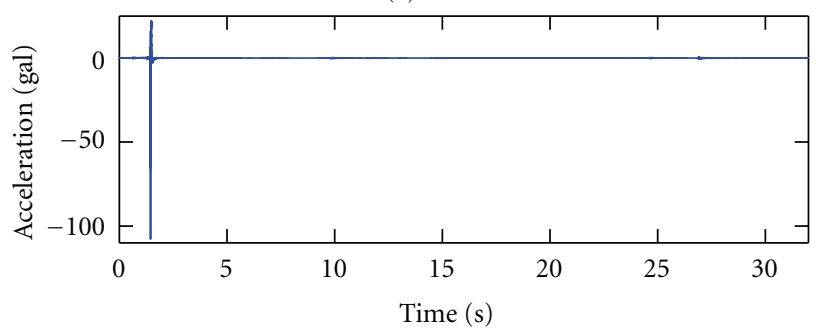

(e)

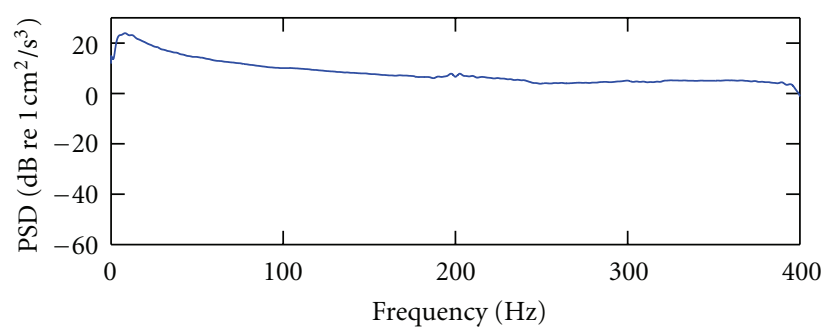

(b)

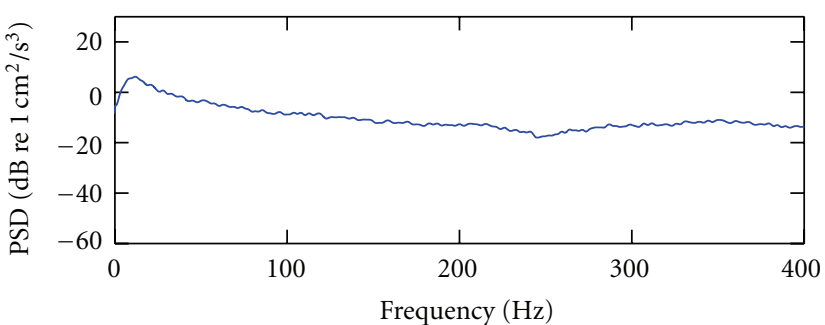

(d)

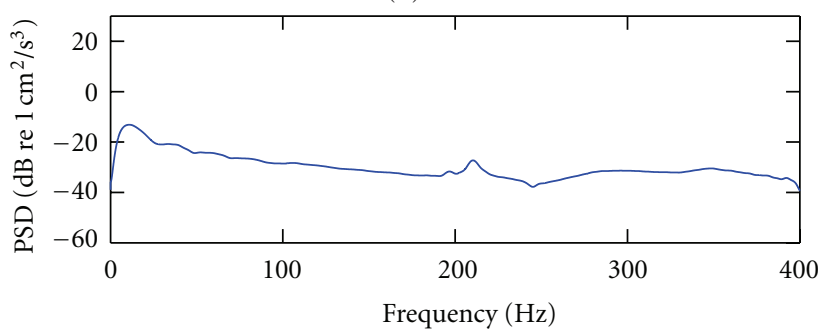

(f)

FIGURE 9: The swept sine (upper), random (middle) and impact (lower) excitations applied on the $74.1 \%$ delaminated specimen and the PSD estimates of the accelerations. 

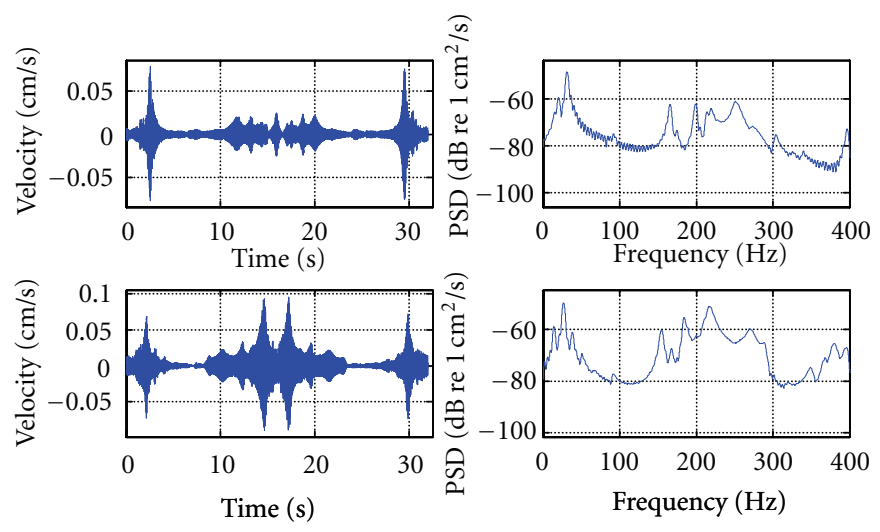

(a)
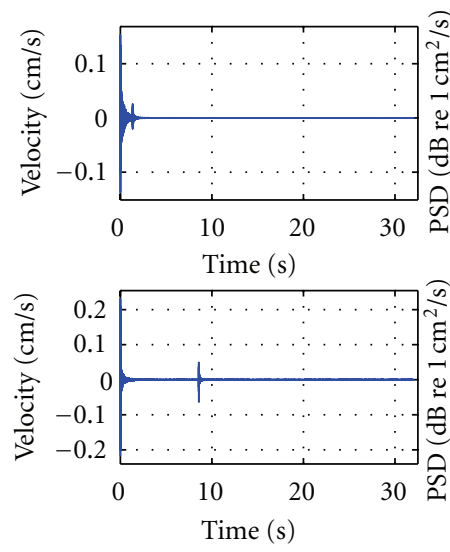

(c)

FIGURE 10: Typical time signals of vertical sensor V4 and PSD estimates of them: upper row is for undamaged model, lower row is for $22.2 \%$ delaminated model: (a) due to swept sine excitations; (b) due to random excitations; (c) due to impact excitations.

the ANSYS models are consistent with those obtained from real measurements; this could validate the ANSYS model to some degree.

It is concluded that the finite element modeling can approximate the undamaged and delaminated concrete slabs for these experimental studies for modal analysis. The results computed by the finite element analysis can be used as supplements for modal identification of the dynamic test data to determine the modal characteristics. The finite element modeling can provide initial investigation for further experimental tests and can also be used effectively for parameter studies.

4.4. Field Test of the Proposed Approach to the Actual Delamination. In the experimental modal testing, the vibration sensors were installed at the top surface. Since vertical modes were concerned for detecting delamination, it does not affect the identification results by placing the sensors either above or under the deck. Therefore, the proposed method will be applicable to actual delamination of concrete decks, in which the sensors were usually installed under the decks. For the
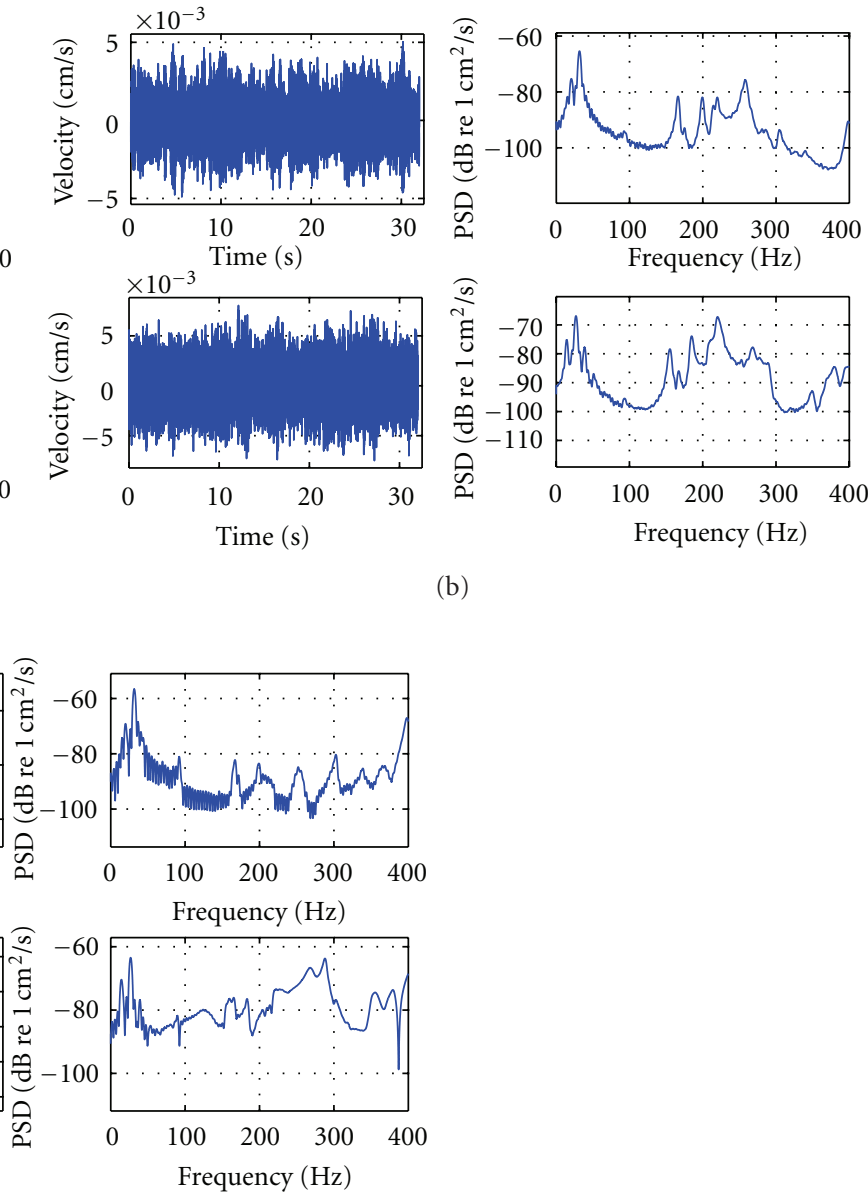

(b)

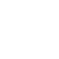

. 


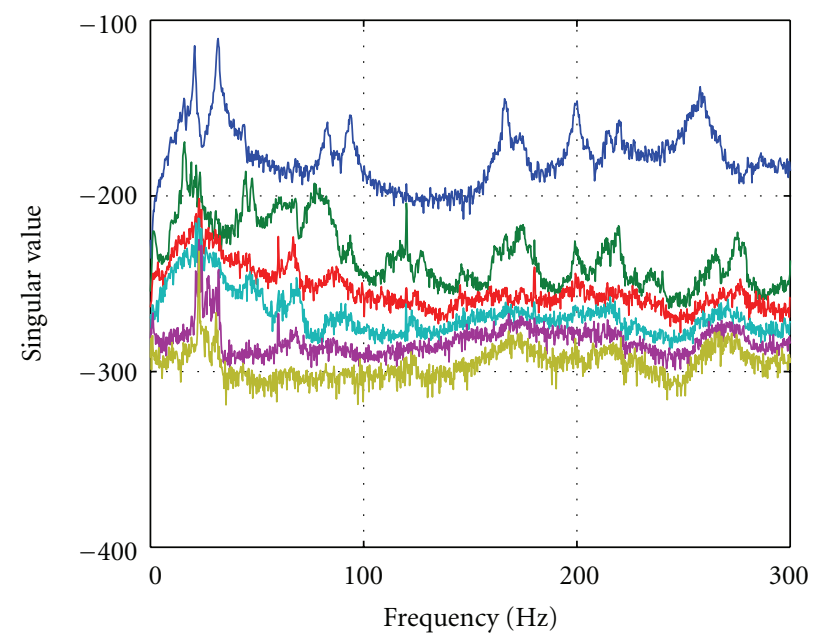

(a)

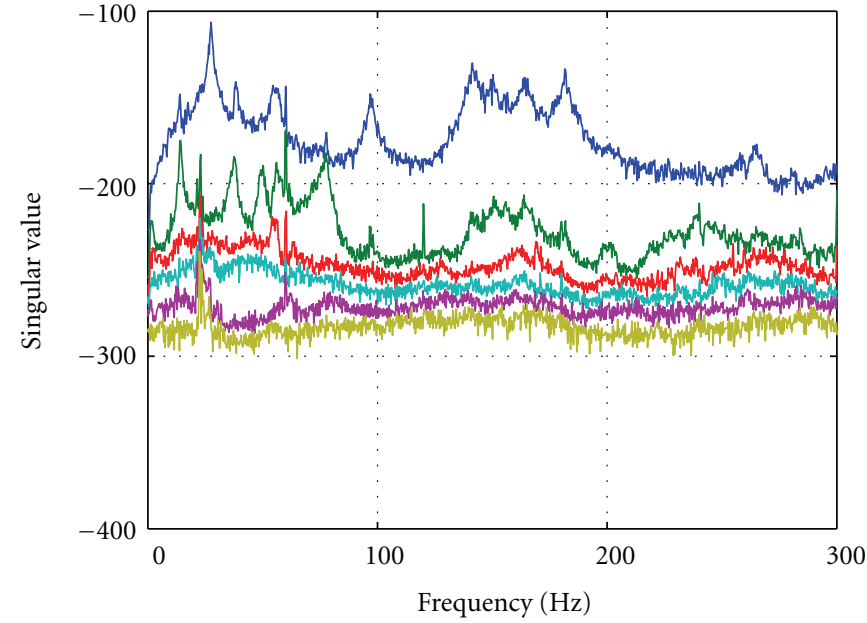

(c)

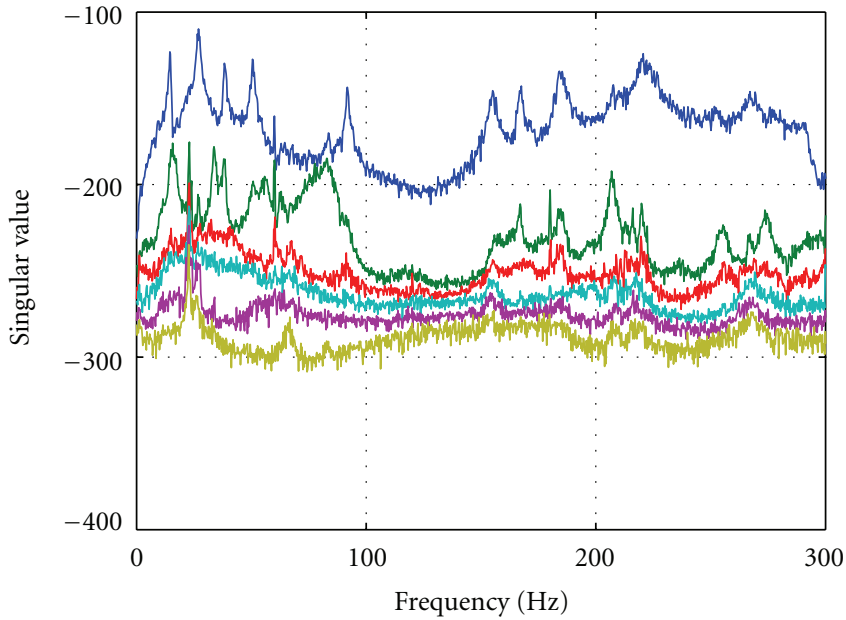

(b)

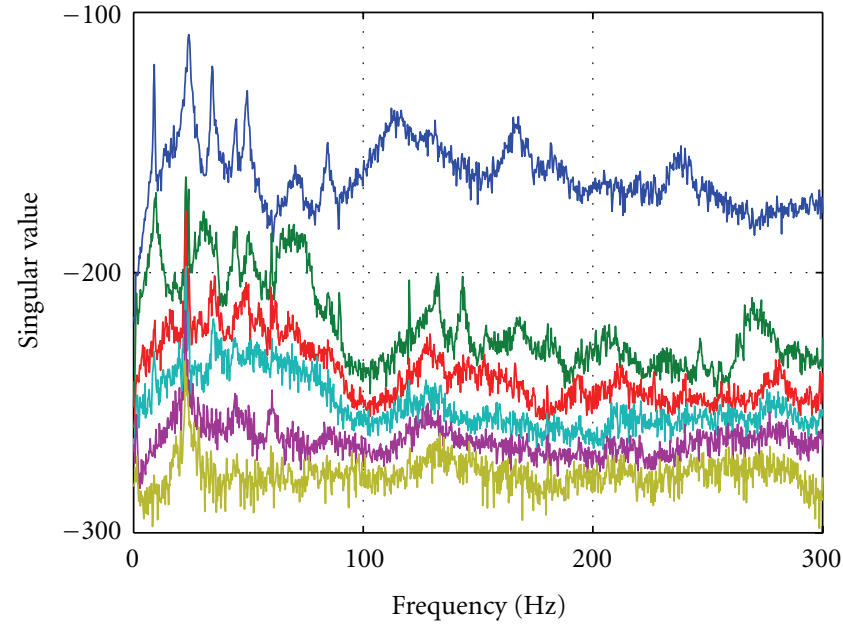

(d)

FIGURE 11: Singular values of PSD of the responses $(V 1 \sim V 6)$ due to random excitation for the tested models: (a) undamaged model; (b) $22.2 \%$ delaminated model; (c) $51.9 \%$ delaminated model; (d) $74.1 \%$ delaminated model.

TABLE 6: Modal frequencies identified by PP, FDD, and SSI $(i=400, n=60)$ methods from experimental specimens under random excitation.

\begin{tabular}{|c|c|c|c|c|c|}
\hline - & - & 1st bending & 2nd bending & 1st bending/torsion & 3rd bending \\
\hline \multirow{3}{*}{ Undamaged } & $\mathrm{PP}(\mathrm{Hz})$ & 31.60 & 68.88 & 84.66 & 165.95 \\
\hline & $\mathrm{FDD}(\mathrm{Hz})$ & 31.77 & 68.03 & 83.04 & 166.08 \\
\hline & $\mathrm{SSI}(\mathrm{Hz})$ & 31.61 & 67.62 & 82.60 & 166.37 \\
\hline \multirow{3}{*}{$22.2 \%$ delaminated } & $\mathrm{PP}(\mathrm{Hz})$ & 26.69 & 51.00 & - & 92.07 \\
\hline & $\mathrm{FDD}(\mathrm{Hz})$ & 27.01 & 50.77 & - & 91.79 \\
\hline & $\mathrm{SSI}(\mathrm{Hz})$ & 26.83 & 50.67 & - & 91.74 \\
\hline \multirow{3}{*}{$51.9 \%$ delaminated } & $\mathrm{PP}(\mathrm{Hz})$ & 27.60 & 55.94 & - & 96.79 \\
\hline & $\mathrm{FDD}(\mathrm{Hz})$ & 27.51 & 54.53 & - & 96.80 \\
\hline & $\mathrm{SSI}(\mathrm{Hz})$ & 27.56 & 55.52 & - & 96.94 \\
\hline \multirow{3}{*}{$74.1 \%$ delaminated } & $\mathrm{PP}(\mathrm{Hz})$ & 24.41 & 44.69 & - & 84.38 \\
\hline & $\mathrm{FDD}(\mathrm{Hz})$ & 24.01 & 44.77 & - & 84.54 \\
\hline & SSI $(\mathrm{Hz})$ & 24.31 & 44.37 & - & 84.63 \\
\hline
\end{tabular}


TABLE 7: The damping ratios identified by using SSI method from experimental specimens.

\begin{tabular}{|c|c|c|c|c|c|}
\hline- & & Undamaged & $22.2 \%$ delaminated & $51.9 \%$ delaminated & $74.1 \%$ delaminated \\
\hline \multirow{2}{*}{ From random responses } & Frequency $(\mathrm{Hz})$ & 31.61 & 26.83 & 27.56 & 24.31 \\
\hline & $\xi(\%)$ & 1.05 & 1.34 & 1.68 & 1.71 \\
\hline \multirow{2}{*}{ From impact responses } & Frequency $(\mathrm{Hz})$ & 31.62 & 26.87 & 27.44 & 9.15 \\
\hline & $\xi(\%)$ & 1.25 & 1.46 & 1.32 & 1.43 \\
\hline
\end{tabular}

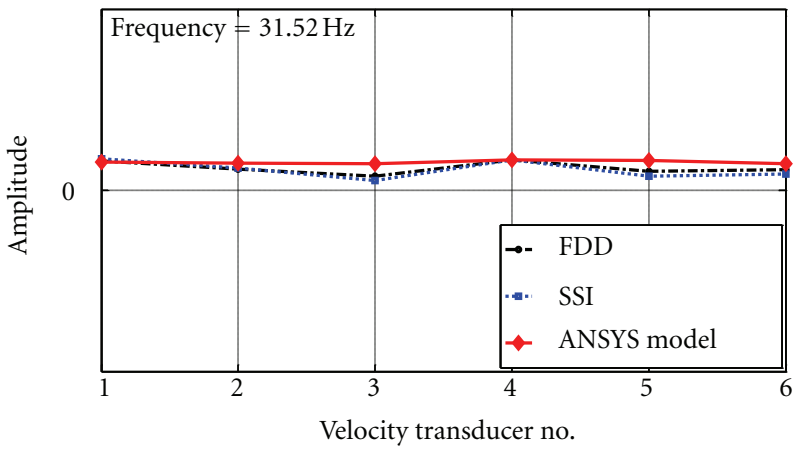

(a)

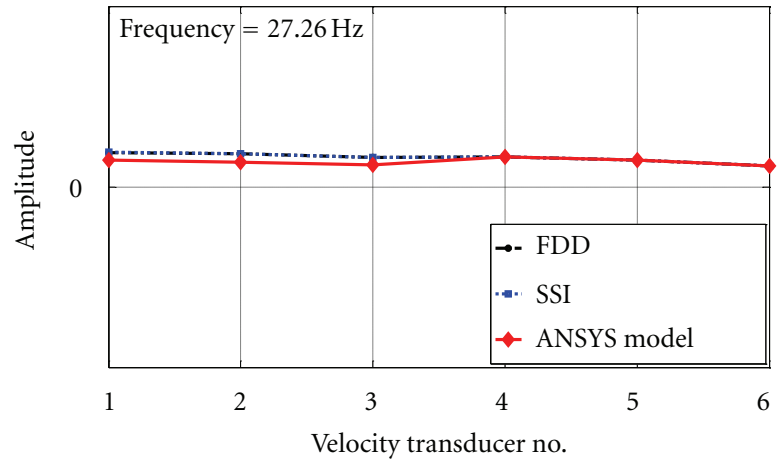

(c)

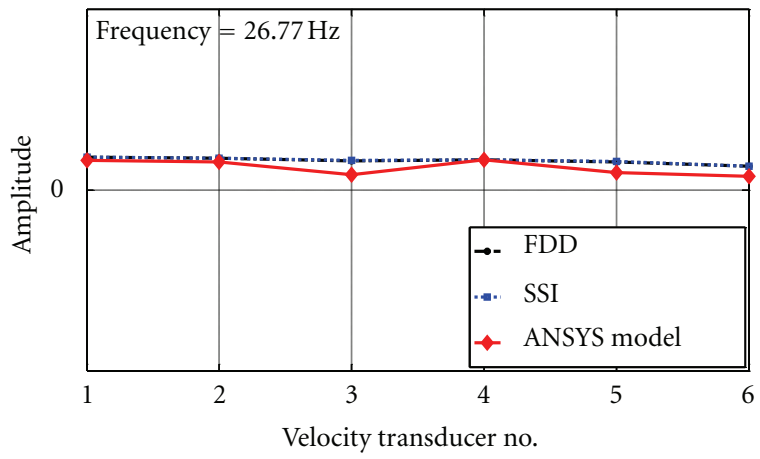

(b)

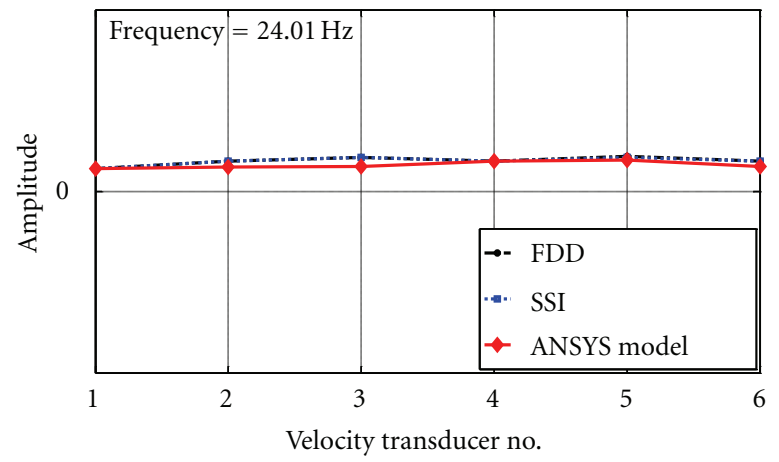

(d)

FIGURE 12: Comparison of mode shapes by FDD, SSI from responses due to random excitation and ANSYS model: (a) undamaged model; (b) $22.2 \%$ delaminated model; (c) $51.9 \%$ delaminated model; (d) $74.1 \%$ delaminated model.

of the delamination on the modal frequencies can be summarized as follows. The higher the modal order, the larger frequency difference between the delaminated models and the undamaged model. The frequency difference also increases with the increase of delamination area. When $1 / 8 \leq A_{\text {delam }} / A_{\text {tot }} \leq 1 / 6$, the changes in the 4 th mode shape can indicate the presence of delamination. When $1 / 6<A_{\text {delam }} / A_{\text {tot }} \leq$ $1 / 4$, the reductions in the $3 r d$ frequency range can indicate the presence of delamination, and the corresponding mode shapes can be used to locate the delaminations. When $A_{\text {delam }} / A_{\text {tot }} \geq 1 / 3$ the reduction in the 1st frequency was greater than $6 \%$, when $A_{\text {delam }} / A_{\text {tot }}=1 / 2$ the reduction in the 1 st frequency was greater than $29.64 \%$, so the changes in the 1st frequency and mode shape may indicate delamination.

From the results of the $1 / 3$ delaminated models at an unsymmetrical location and a symmetrical location, it is observed that the location of the delamination can have significant effect on modal parameters. The more unsymmetrical the delamination area was with respect to the total area, the bigger the changes in the frequencies and mode shapes. For example, for the cases in this paper, the changes in the 1st frequencies are $6.39 \%$ and $3.10 \%$ for the unsymmetrical and symmetrical delaminated models, respectively.

Some specific modes were more sensitive to delamination than their adjacent modes and are shown to be excellent indicators of delamination. For example, the changes in the 4th modal frequencies of the $A_{\text {delam }} / A_{\text {tot }}=1 / 6,1 / 5,1 / 4,1 / 3$ unsymmetrical 1 delaminated models are bigger than their neighboring modes.

(b) For the delaminated models, it was shown that amplitudes of delaminated areas in the mode shapes were significantly irregular compared to the undamaged models. This feature can be used to detect and locate 
TABLE 8: Comparison of modal frequencies by ANSYS modeling and FDD of the responses of experimental specimens under random excitation.

\begin{tabular}{|c|c|c|c|c|c|}
\hline- & - & 1st bending & 2nd bending & 1st bending/torsion & 3rd bending \\
\hline \multirow{2}{*}{$0 \%$ delaminated } & ANSYS (Hz) & 31.46 & 69.13 & 81.68 & 165.80 \\
\hline & FDD $(\mathrm{Hz})$ & 31.77 & 68.03 & 83.04 & 166.08 \\
\hline \multirow{2}{*}{$22.2 \%$ delaminated } & ANSYS (Hz) & 27.38 & 51.99 & 65.63 & 91.71 \\
\hline & $\mathrm{FDD}(\mathrm{Hz})$ & 27.01 & 50.77 & - & 91.79 \\
\hline \multirow{2}{*}{$51.9 \%$ delaminated } & ANSYS (Hz) & 26.98 & 50.81 & 65.27 & 96.99 \\
\hline & $\mathrm{FDD}(\mathrm{Hz})$ & 27.51 & 54.53 & - & 96.80 \\
\hline \multirow{2}{*}{$74.1 \%$ delaminated } & ANSYS (Hz) & 24.91 & 42.78 & 60.47 & 81.39 \\
\hline & FDD $(\mathrm{Hz})$ & 24.01 & 44.77 & - & 84.54 \\
\hline
\end{tabular}

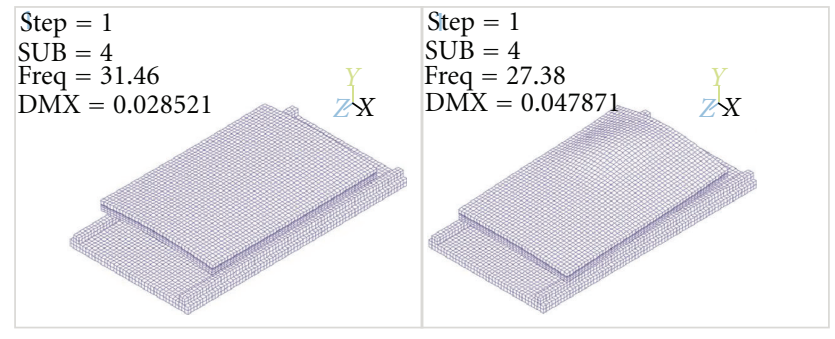

Figure 13: The comparison of the 3rd mode shapes for the undamaged (left) and $22.2 \%$ delaminated (right) specimens.

delamination. The limitation is that it requires a dense layout of sensors to obtain mode shapes and quantify the irregular shapes. With the development of new sensor technology and algorithms, this problem may be solved satisfactorily.

(c) The effects of the support conditions on the applicability of the proposed approach were studied. It was concluded that the proposed approach applies to various support conditions that include concrete decks supported on beams.

Experimental studies were conducted on reinforced concrete plates with different delamination sizes. The modal characteristics were extracted from the dynamic responses and analyzed. Finite element models of concrete slabs were developed using ANSYS. Conclusions are drawn as follows.

(a) The response measurements show that, if given same external excitation, the amplitudes of the delaminated models were obviously larger than those of the undamaged model.

(b) Changes in frequencies and mode shapes can indicate the occurrence and degree of delamination. The frequencies decrease with the increase of delamination sizes. The 1st modal frequency decreased $43 \%$ for the $74.1 \%$ delaminated specimen when compared to the undamaged specimen. The changes in higher modal frequencies are larger. The experimental results show that the damping ratios increase with the increase of delamination sizes. Damping can assist in the delamination identification, but it alone is not suitable as a delamination indicator. It demonstrated that the mode shapes have abrupt changes in the delamination areas of the specimens.
When other damage exists, for example, concrete spalling and rock pocket, more effort is needed to determine whether the changes in modal characteristics can be attributed specifically to delamination. Further investigations of damage characteristics of delamination may be needed.

(c) It is beneficial to use multiple identification methods to ensure correct identification results. The frequencies identified by the PP, FDD, and SSI methods agree well; the maximum difference between the 1st frequencies by these methods is less than $4.8 \%$. The mode shapes that are extracted by FDD and SSI are shown to be identical.

(d) In the finite element modeling, the frequencies and mode shapes calculated by the FE models agreed well with those identified from test data, among which the differences between the first three modal frequencies by ANSYS model and FDD method from test data are within $7 \%$. Therefore finite element models can approximately model delaminated concrete slabs for modal analysis.

This work provides useful information for practical delamination detection of bridge decks by vibration-based health monitoring systems. The experimental as well as numerical models were intended to simulate a portion of real concrete deck on beams. Therefore, the results were applicable to the concrete panels on girders, while the delamination detection approach in this study is also an alternative way for other structural forms.

For the future work, experimental modal testing with more stable and practical boundary conditions is needed. Stabilization diagrams are suggested to be used for obtaining more accurate modal characteristics. Further work is necessary for developing more sensitive delamination indicators and more accurate finite element models. Additionally, field tests for actual delamination detection using the actual vibration sensors under bridge deck are highly recommended. It is anticipated that the proposed new methodology can be applied to an actual bridge deck in five years.

\section{Acknowledgment}

The research work was financially supported by the Utah Transportation Center (UTC) and the Utah Department of Transportation (UDOT). 


\section{References}

[1] J. P. Warhus, J. E. Mast, and S. D. Nelson, "Imaging radar for bridge deck inspection," in Proceedings of the Nondestructive Evaluation of Aging Bridges and Highways, pp. 296-305, Oakland, Calif, USA, June 1995.

[2] J. Broomfield, Corrosion of Steel in Concrete, Understanding, Investigating, and Repair, E \& FN Spon, London, UK, 2nd edition, 1997.

[3] C. Q. Li, J. J. Zheng, W. Lawanwisut, and R. E. Melchers, "Concrete delamination caused by steel reinforcement corrosion," Journal of Materials in Civil Engineering, vol. 19, no. 7, pp. 591600, 2007.

[4] N. Gucunski, Z. Wang, T. Fang, and A. Maher, "Rapid bridge deck condition assessment using three-dimensional visualization of impact echo data," in Proceedings of the NonDestructive Testing in Civil Engineering (NDTCE '09), Nantes, France, 2009.

[5] Y. Zou, L. Tong, and G. P. Steven, "Vibration-based modeldependent damage (delamination) identification and health monitoring for composite structures-a review," Journal of Sound and Vibration, vol. 230, no. 2, pp. 357-378, 2000.

[6] S. H. Diaz Valdes and C. Soutis, "Delamination detection in composite laminates from variations of their modal characteristics," Journal of Sound and Vibration, vol. 228, no. 1, pp. 1-9, 1999.

[7] C. P. Ratcliffe and W. J. Bagaria, "Vibration technique for locating delamination in a composite beam," AIAA Journal, vol. 36, no. 6, pp. 1074-1077, 1998.

[8] Z. Wei, L. H. Yam, and L. Cheng, "Delamination assessment of multilayer composite plates using model-based neural networks," JVC/Journal of Vibration and Control, vol. 11, no. 5, pp. 607-625, 2005.

[9] Y. J. Yan and L. H. Yam, "Detection of delamination damage in composite plates using energy spectrum of structural dynamic responses decomposed by wavelet analysis," Computers and Structures, vol. 82, no. 4-5, pp. 347-358, 2004.

[10] S. Xing, M. W. Halling, and P. J. Barr, "Delamination detection and location in concrete deck by modal identification," in Proceedings of the Structures Congress, pp. 741-751, Orlando, Fla, USA, 2010.

[11] S. Xing, M. W. Hailing, and P. J. Barr, "Delamination detection in concrete plates using output-only vibration measurements," in Proceedings of the 29th International Modal Analysis Conference (IMAC'11), pp. 255-262, Jacksonville, Fla, USA, February 2011.

[12] R. Brincker, L. Zhang, and P. Andersen, "Modal identification from ambient responses using frequency domain decomposition," in Proceedings of the International Modal Analysis Conference (IMAC'00), pp. 625-630, San Antonio, Tex, USA, 2000.

[13] R. Brincker, C. E. Ventura, and P. Anderson, "Damping estimation by frequency domain decomposition," in Proceedings of the International Modal Analysis Conference (IMAC '01), pp. 698-703, Kissimmee, Fla, USa, 2001.

[14] P. Van Overschee and B. De Moor, "Subspace algorithms for the stochastic identification problem," Automatica, vol. 29, no. 3, pp. 649-660, 1993.

[15] P. Van Overschee and B. De Moor, Subspace Identification for Linear Systems: Theory, Implementation, Kluwer Academic, Dordrecht, The Netherlands, 1996.

[16] B. Peeters and G. De Roeck, "Reference-based stochastic subspace identification for output-only modal analysis," Mechanical Systems and Signal Processing, vol. 13, no. 6, pp. 855-878, 1999.
[17] T. Katayama, Subspace Methods for System Identification, Springer, Englewood Cliffs, New Jersey, USA, 1st edition, 2005.

[18] AnsysH Release 10.0 ANSYS theory reference, 2005.

[19] S. Rajendran and D. Q. Song, "Finite element modeling of delamination buckling of composite panel using Ansys," in Proceedings of the 2nd Asian ANSYS User Conference, Singapore, 1998.

[20] A. Leissa, "The free vibration of rectangular plates," Journal of Sound and Vibration, vol. 31, no. 3, pp. 257-293, 1973.

[21] K. M. Liew, Y. Xiang, S. Kitipornchai, and C. M. Wang, Vibration of Mindlin Plates: Programming the P-Version Ritz Method, Elsevier Science, Oxford, UK, 1998.

[22] Forest Products Laboratory, Wood Handbook: Wood as an Engineering Material, U.S. Department of Agriculture, Forest Service, Forest Products Laboratory, Madison, Wis, USA, 2010.

[23] R. S. McBurney and J. T. DROW, "The elastic properties of wood Young's moduli and poisson's ratios of douglas-fir and their relations to moisture content," Report no. 1528-D, Forest Products Laboratory, Forest Product Service, U.S. Department of Agriculture, 1962.

[24] A. Sliker, “Measuring Poisson's ratios in wood-a method for measuring Poisson's ratios along with Young's moduli in wood is described by the author," Experimental Mechanics, vol. 12, no. 5, pp. 239-242, 1972. 

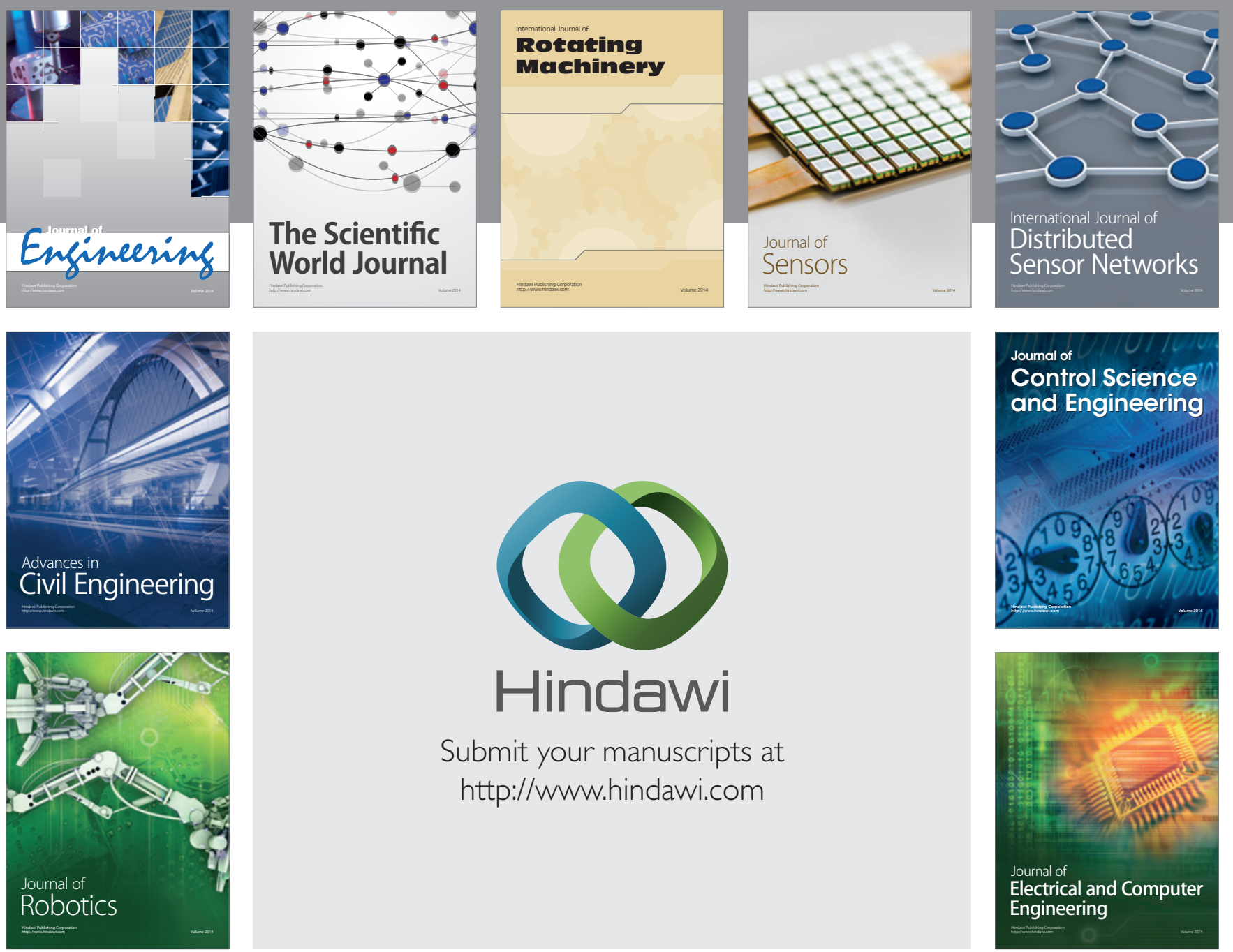

Submit your manuscripts at

http://www.hindawi.com
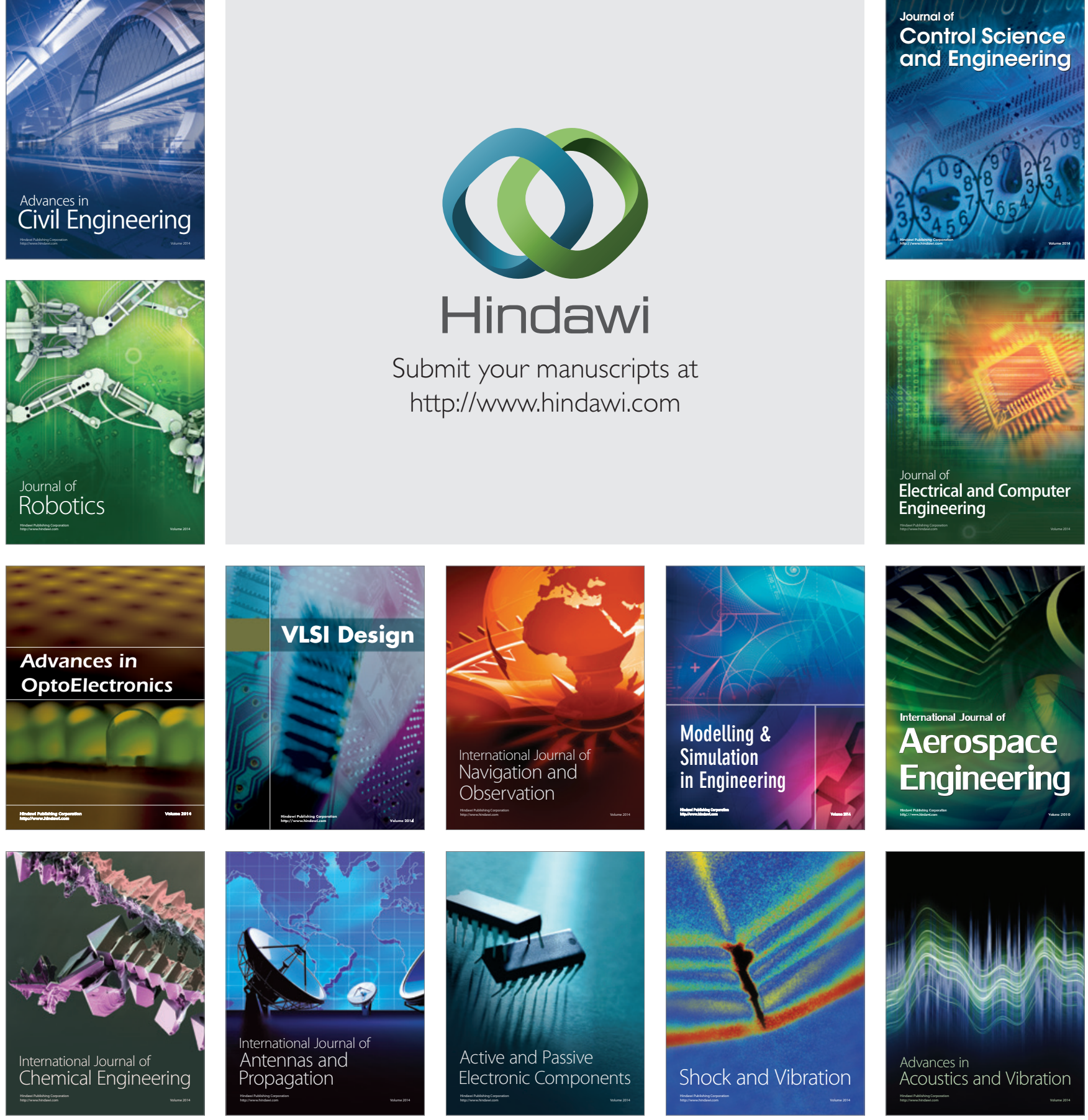